Supporting Information

\title{
Bafilomycins and Odoriferous Sesquiterpenoids from Streptomyces albolongus Isolated from Elephas maximus Feces
}

Nan Ding, ${ }^{+, \ddagger}$ Yi Jiang, ${ }^{\S}$ Li Han, ${ }^{\dagger}$ Xiu Chen, ${ }^{\dagger}$ Jian Ma, ${ }^{+}$Xiaodan Qu, ${ }^{+}$Yu Mu, ${ }^{\dagger}$ Jiang Liu, ${ }^{+}$Liya Li, ${ }^{+}$Chenglin Jiang, ${ }^{\S}$ Xueshi Huang ${ }^{*}+$

${ }^{+}$Institute of Microbial Pharmaceuticals, College of Life and Health Sciences, Northeastern University, Shenyang 110819, P. R. China

${ }^{\ddagger}$ Laboratory of Metabolic Disease Research and Drug Development, China Medical University, Shenyang 110001, P. R. China

$\S$ Yunnan Institute of Microbiology, Yunnan University, Kunming 650091, P. R. China

*To whom correspondence should be addressed.

Tel: 0086-24-83656122. Fax: 0086-24-83656122. E-mail: huangxs@mail.neu.edu.cn. 
Figure S1. HRESI-MS spectrum of the new compound $\mathbf{1}$

Figure S2. ${ }^{1} \mathrm{H}$ NMR (600 MHz, DMSO- $\left.d_{6}\right)$ spectrum of the new compound 1

Figure S3. ${ }^{13} \mathrm{C}$ NMR $\left(150 \mathrm{MHz}, \mathrm{DMSO}-d_{6}\right)$ spectrum of the new compound 1

Figure S4. HSQC spectrum of the new compound 1

Figure S5. HMBC spectrum of the new compound 1

Figure S6. COSY spectrum of the new compound 1

Figure S7. NOESY spectrum of the new compound 1

Figure S8. HRESI-MS spectrum of the new compound 2

Figure S9. ${ }^{1} \mathrm{H}$ NMR $\left(600 \mathrm{MHz}\right.$, DMSO- $\left.d_{6}\right)$ spectrum of the new compound 2

Figure S10. ${ }^{13} \mathrm{C}$ NMR $\left(150 \mathrm{MHz}, \mathrm{DMSO}-d_{6}\right)$ spectrum of the new compound 2

Figure S11. HSQC spectrum of the new compound 2

Figure S12. HMBC spectrum of the new compound 2

Figure S13. COSY spectrum of the new compound 2

Figure S14. NOESY spectrum of the new compound 2

Figure S15. HRESI-MS spectrum of the new compound $\mathbf{3}$

Figure S16. ${ }^{1} \mathrm{H}$ NMR (600 MHz, DMSO- $\left.d_{6}\right)$ spectrum of the new compound 3

Figure S17. ${ }^{13} \mathrm{C}$ NMR $\left(150 \mathrm{MHz}\right.$, DMSO- $\left.d_{6}\right)$ spectrum of the new compound 3

Figure S18. HSQC spectrum of the new compound $\mathbf{3}$ 
Figure S19. HMBC spectrum of the new compound 3

Figure S20. COSY spectrum of the new compound $\mathbf{3}$

Figure S21. NOESY spectrum of the new compound 3

Figure S22. HRESI-MS spectrum of the new compound $\mathbf{1 0}$

Figure S23. ${ }^{1} \mathrm{H}$ NMR (600 MHz, DMSO- $d_{6}$ ) spectrum of the new compound 10

Figure S24. ${ }^{13} \mathrm{C}$ NMR $\left(150 \mathrm{MHz}, \mathrm{DMSO}-d_{6}\right)$ spectrum of the new compound 10

Figure S25. HSQC spectrum of the new compound $\mathbf{1 0}$

Figure S26. HMBC spectrum of the new compound $\mathbf{1 0}$

Figure S27. COSY spectrum of the new compound $\mathbf{1 0}$

Figure S28. NOESY spectrum of the new compound $\mathbf{1 0}$

Figure S29. HRESI-MS spectrum of the new compound 11

Figure S30. ${ }^{1} \mathrm{H}$ NMR (600 MHz, DMSO- $d_{6}$ ) spectrum of the new compound 11

Figure S31. ${ }^{13} \mathrm{C}$ NMR (150 MHz, DMSO- $\left.d_{6}\right)$ spectrum of the new compound 11

Figure S32. HSQC spectrum of the new compound 11

Figure S33. HMBC spectrum of the new compound 11

Figure S34. COSY spectrum of the new compound $\mathbf{1 1}$

Figure S35. NOESY spectrum of the new compound $\mathbf{1 1}$ 


\section{User Spectra}

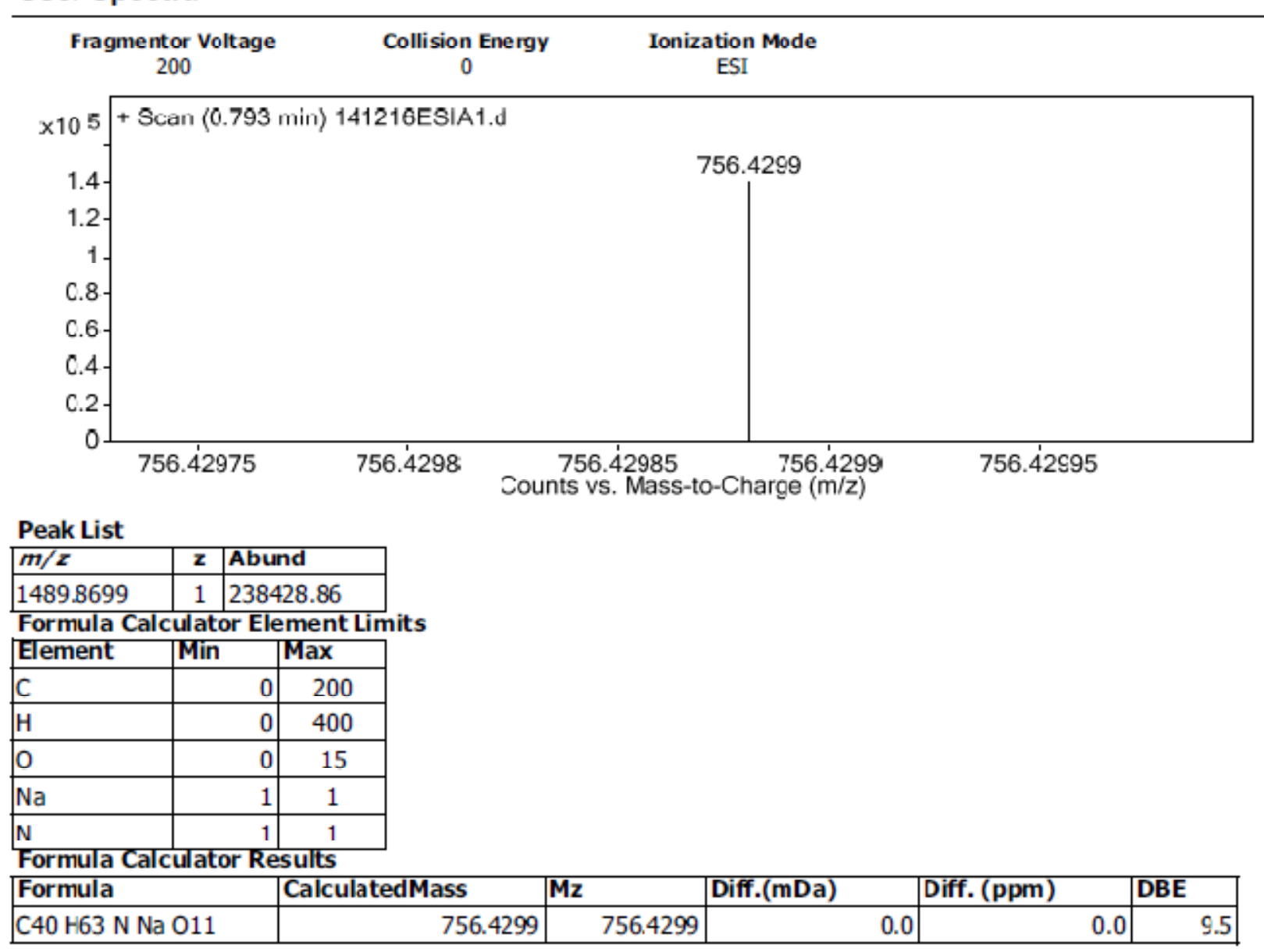

Figure S1. HRESI-MS spectrum of the new compound 1 


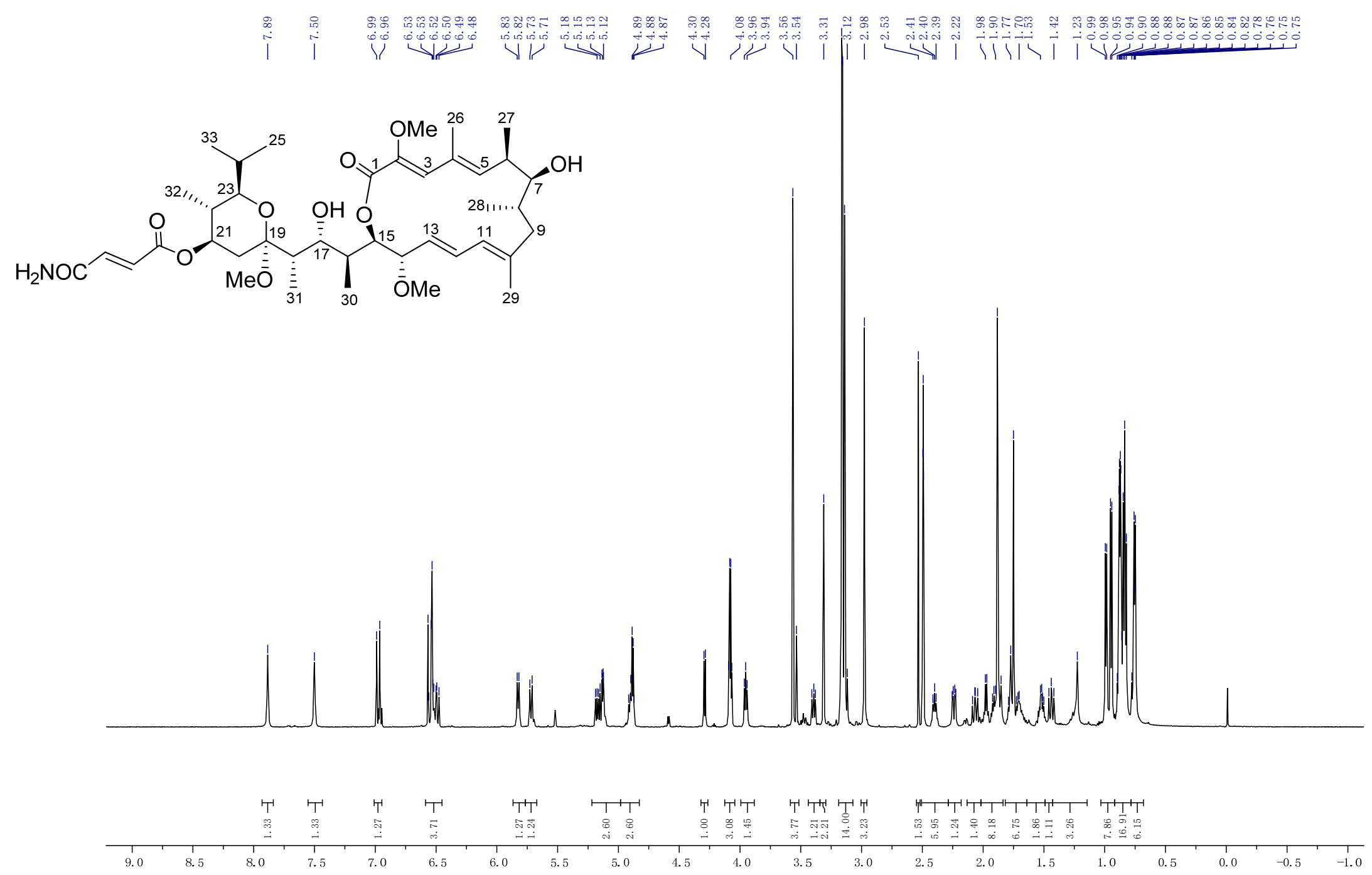

Figure S2. ${ }^{1} \mathrm{H}$ NMR $\left(600 \mathrm{MHz}, \mathrm{DMSO}-d_{6}\right)$ spectrum of the new compound 1 

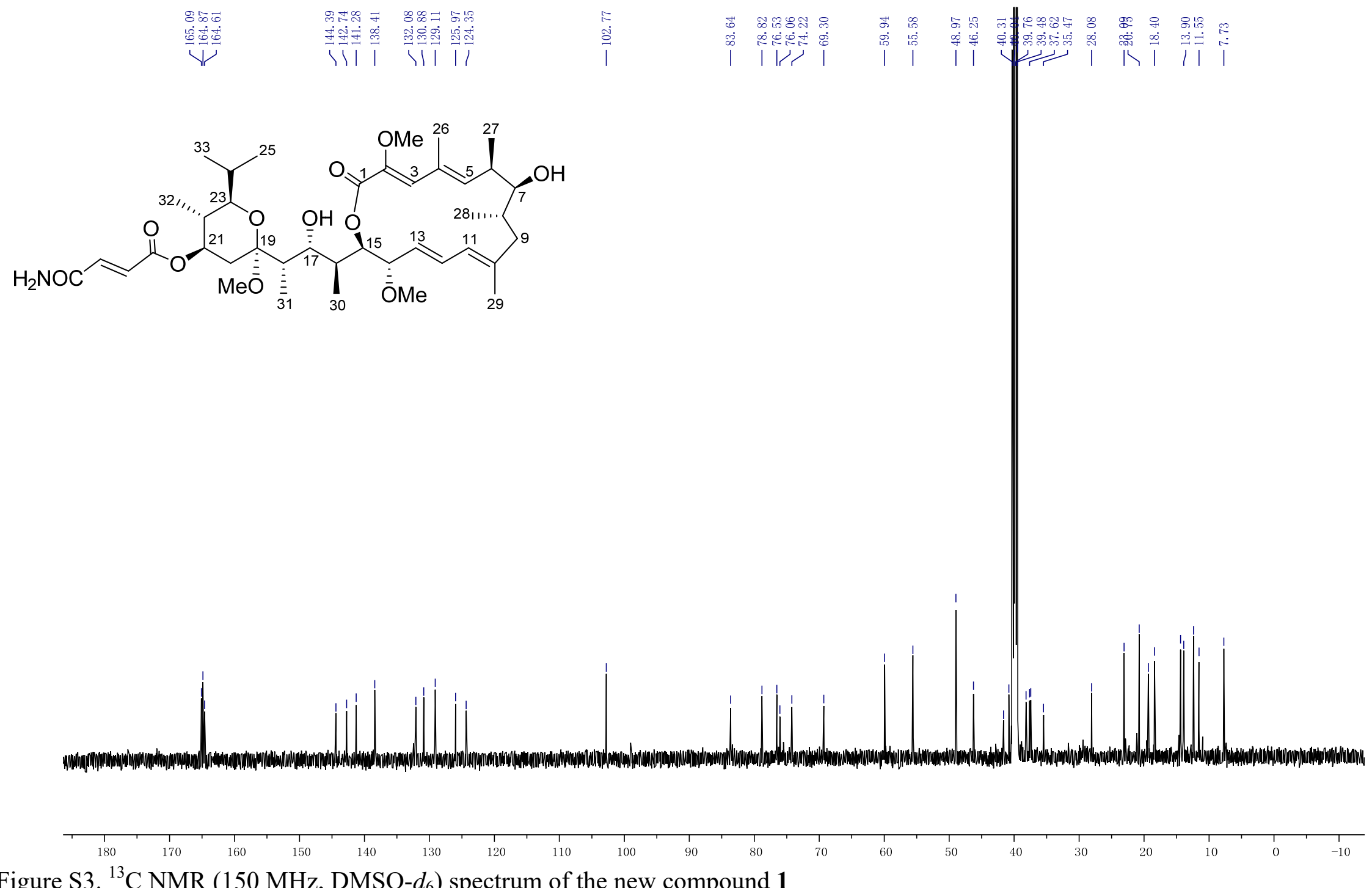

Figure S3. ${ }^{13} \mathrm{C}$ NMR $\left(150 \mathrm{MHz}, \mathrm{DMSO}-d_{6}\right)$ spectrum of the new compound 1 


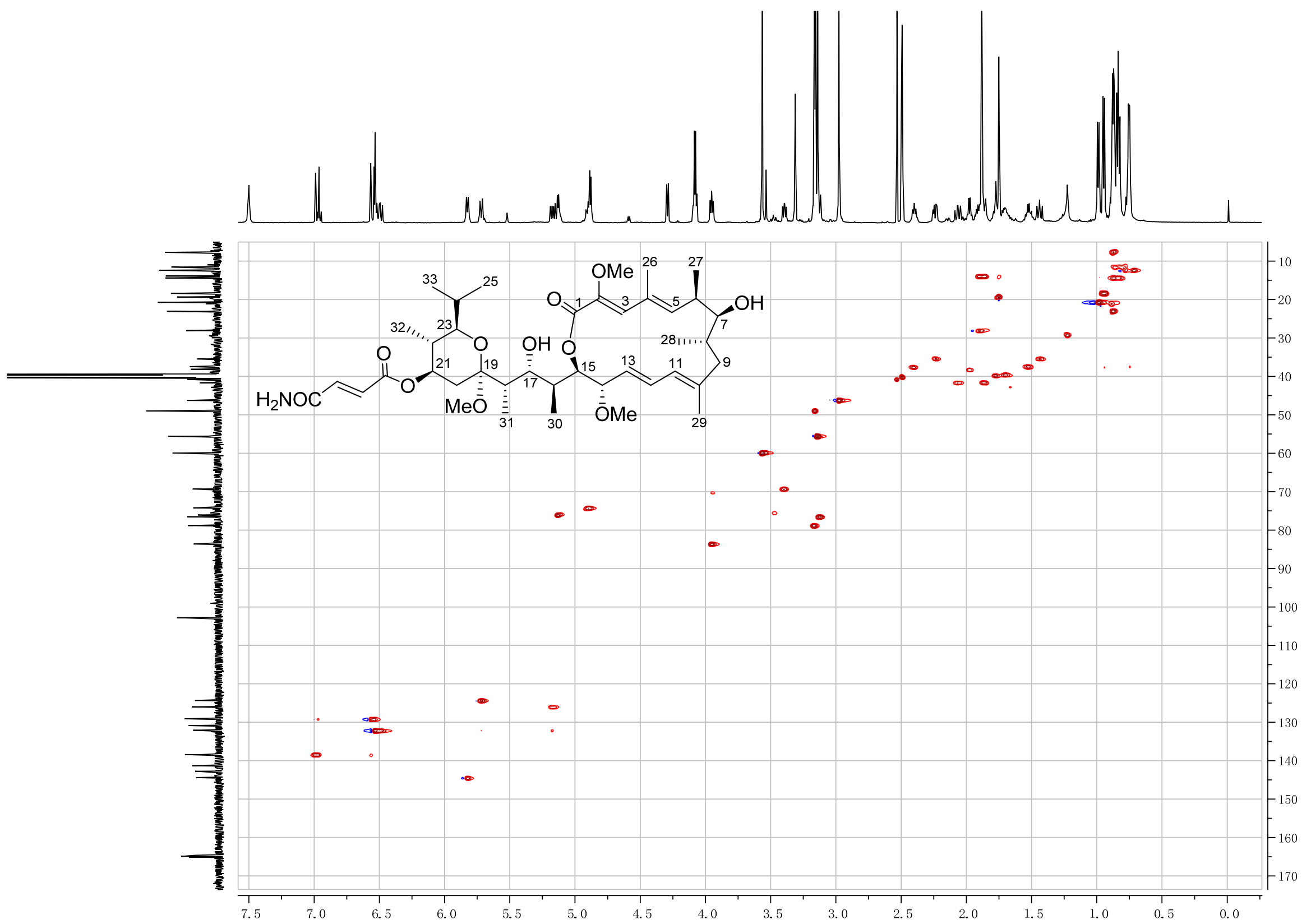

Figure S4. HSQC spectrum of the new compound 1 


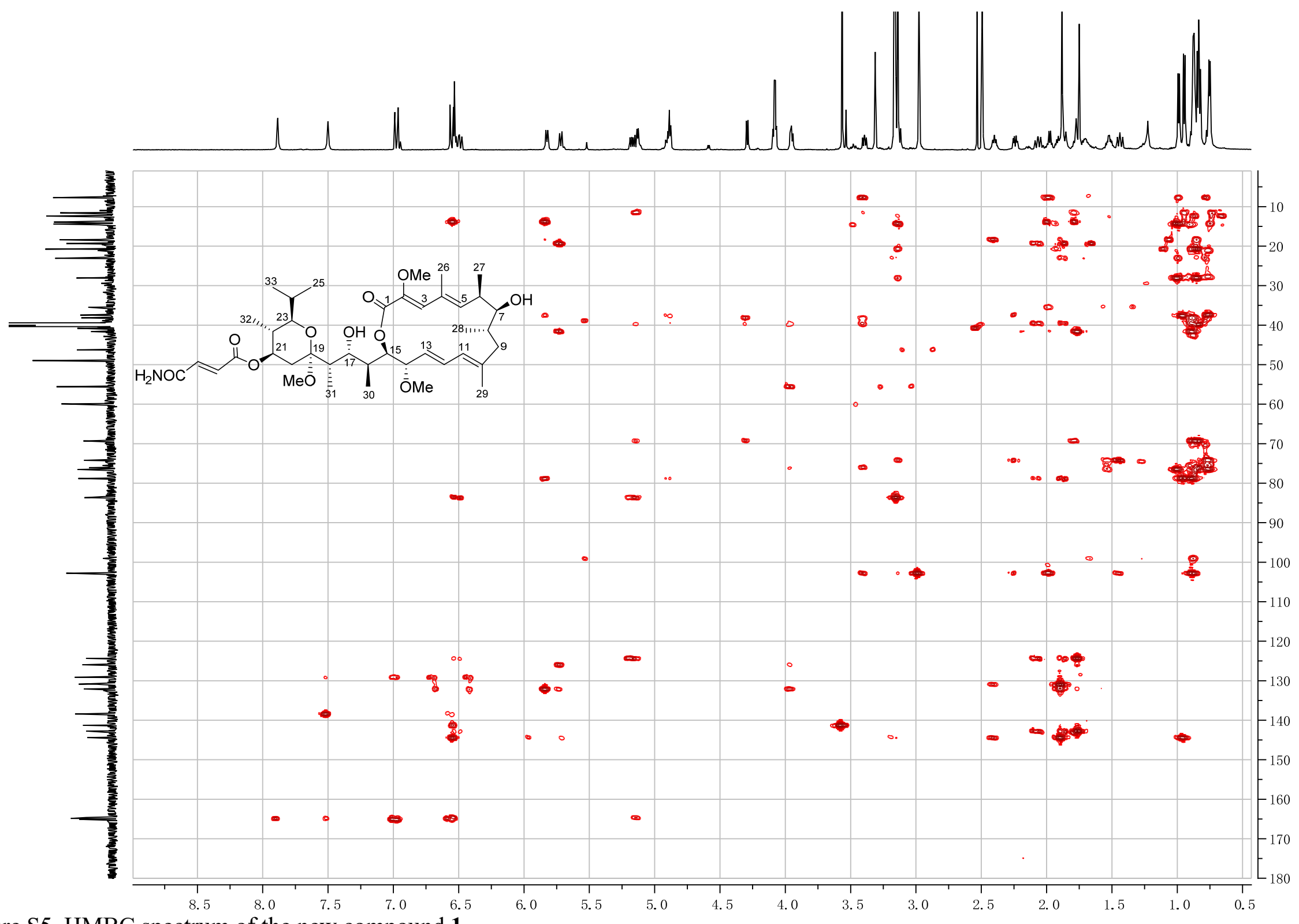

Figure S5. HMBC spectrum of the new compound 1 


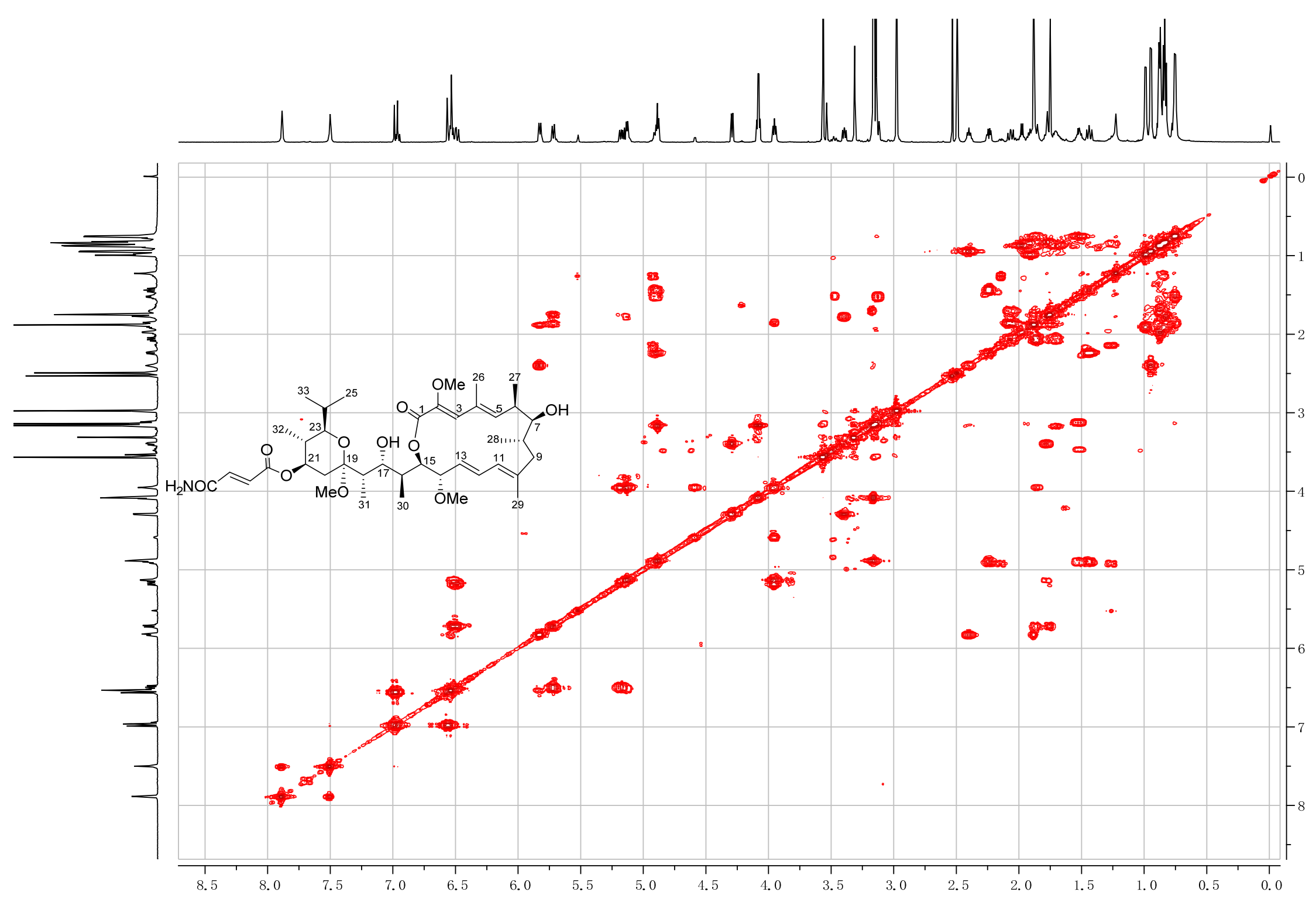

Figure S6. COSY spectrum of the new compound 1 


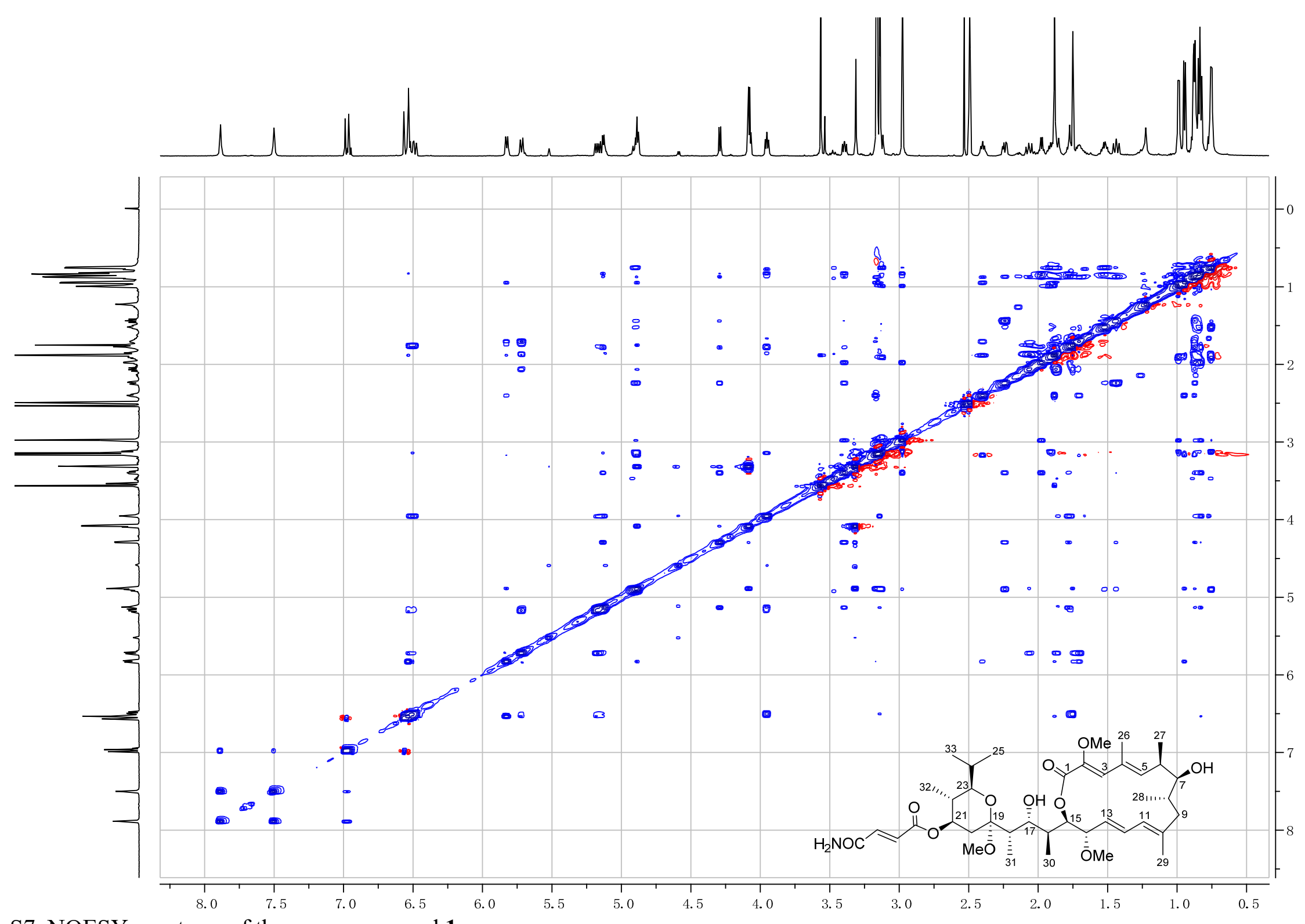

Figure S7. NOESY spectrum of the new compound 1 
User Spectra

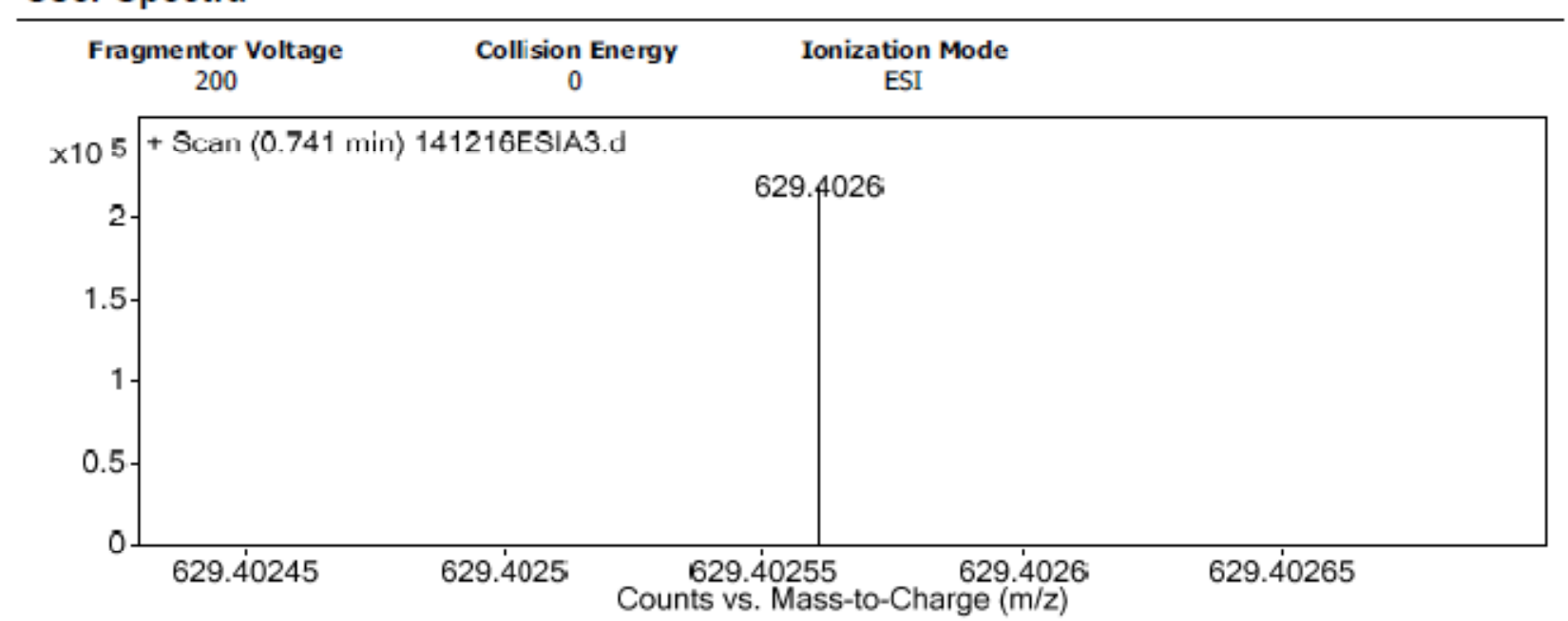

Peak List

\begin{tabular}{|l|l|l|l|l|}
\hline $\boldsymbol{m} / \boldsymbol{z}$ & $\mathbf{z}$ & Abund & Formula & Ion \\
\hline 629.4026 & 1 & 217508.84 & C35 H58 Na O8 & M+ \\
\hline
\end{tabular}

Formula Calculator Element Limits

Element

\begin{tabular}{|l|r|c|}
\hline Element & Min & Max \\
\hline $\mathrm{C}$ & 0 & 200 \\
\hline $\mathrm{H}$ & 0 & 400 \\
\hline $\mathrm{O}$ & 0 & 15 \\
\hline $\mathrm{Na}$ & 1 & 1 \\
\hline
\end{tabular}

Formula Calculator Results

\begin{tabular}{|l|r|r|r|r|r|}
\hline Formula & CalculatedMass & Mz & Diff.(mDa) & Diff. (ppm) & DBE \\
\hline C35 H58 Na 08 & 629.4029 & 629.4026 & 0.3 & 0.5 & 6.5 \\
\hline
\end{tabular}

Figure S8. HRESI-MS spectrum of the new compound 2 


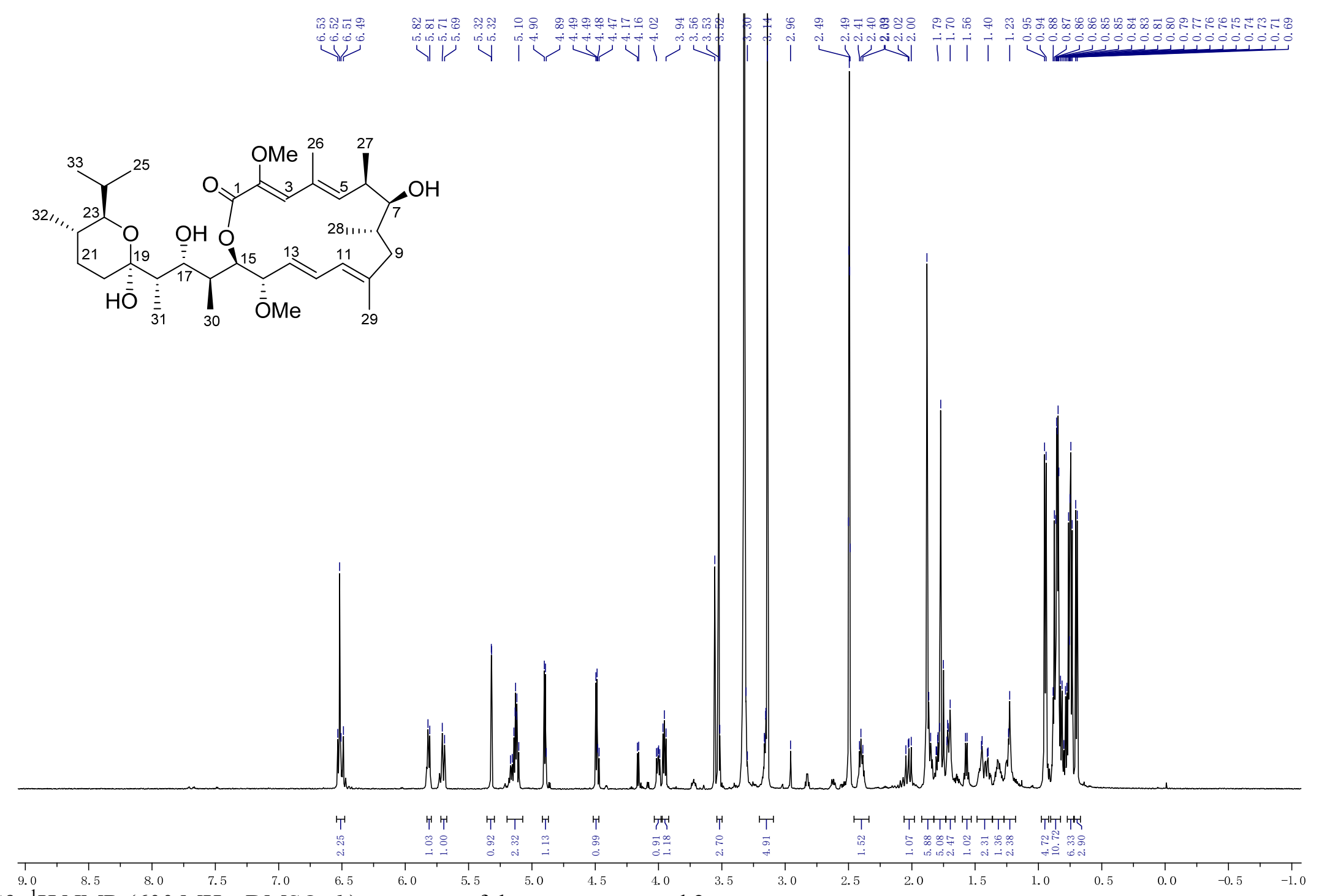

Figure S9. ${ }^{1} \mathrm{H}$ NMR $\left(600 \mathrm{MHz}\right.$, DMSO- $\left.d_{6}\right)$ spectrum of the new compound 2 

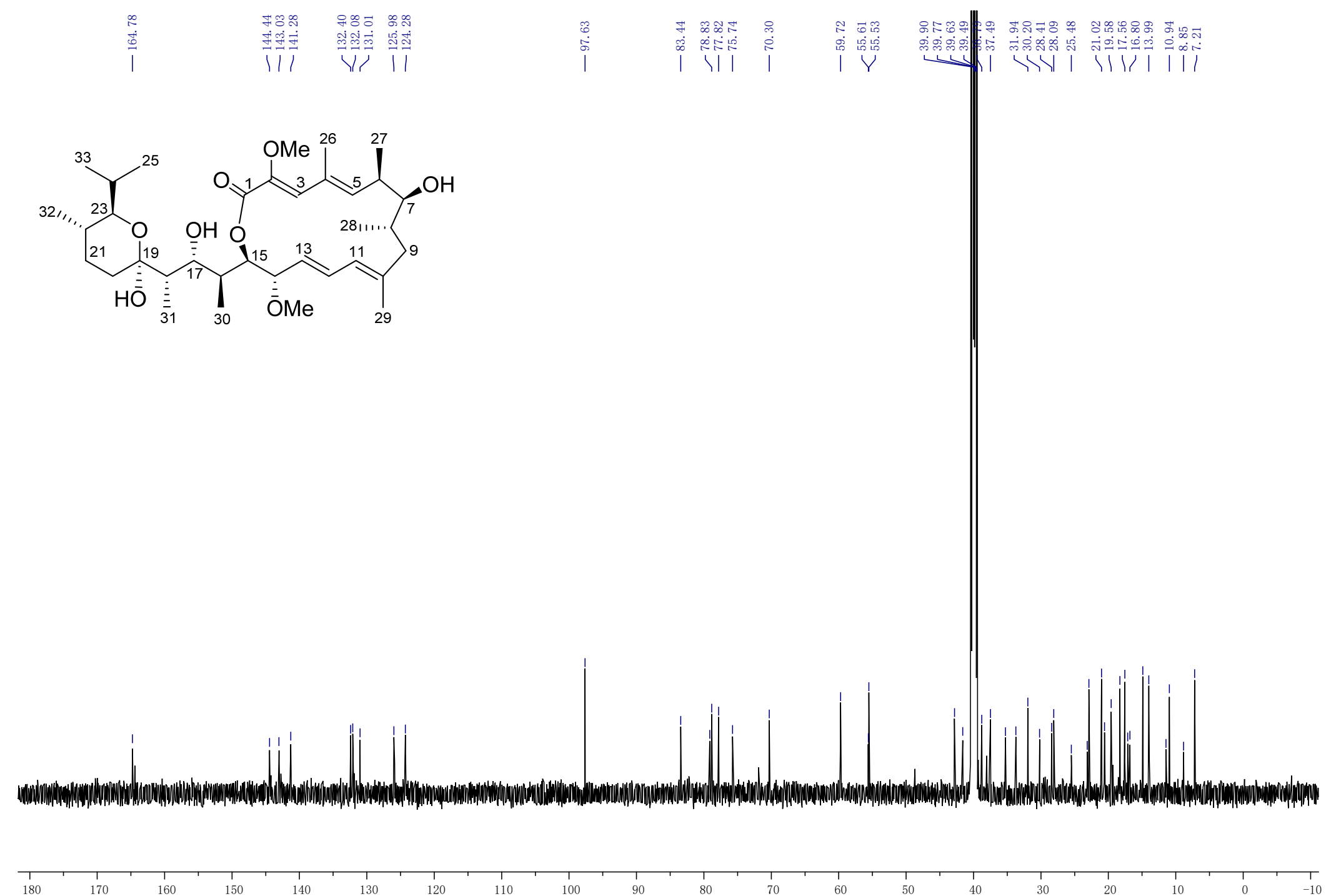

Figure S10. ${ }^{13} \mathrm{C}$ NMR $\left(150 \mathrm{MHz}\right.$, DMSO- $\left.d_{6}\right)$ spectrum of the new compound 2 


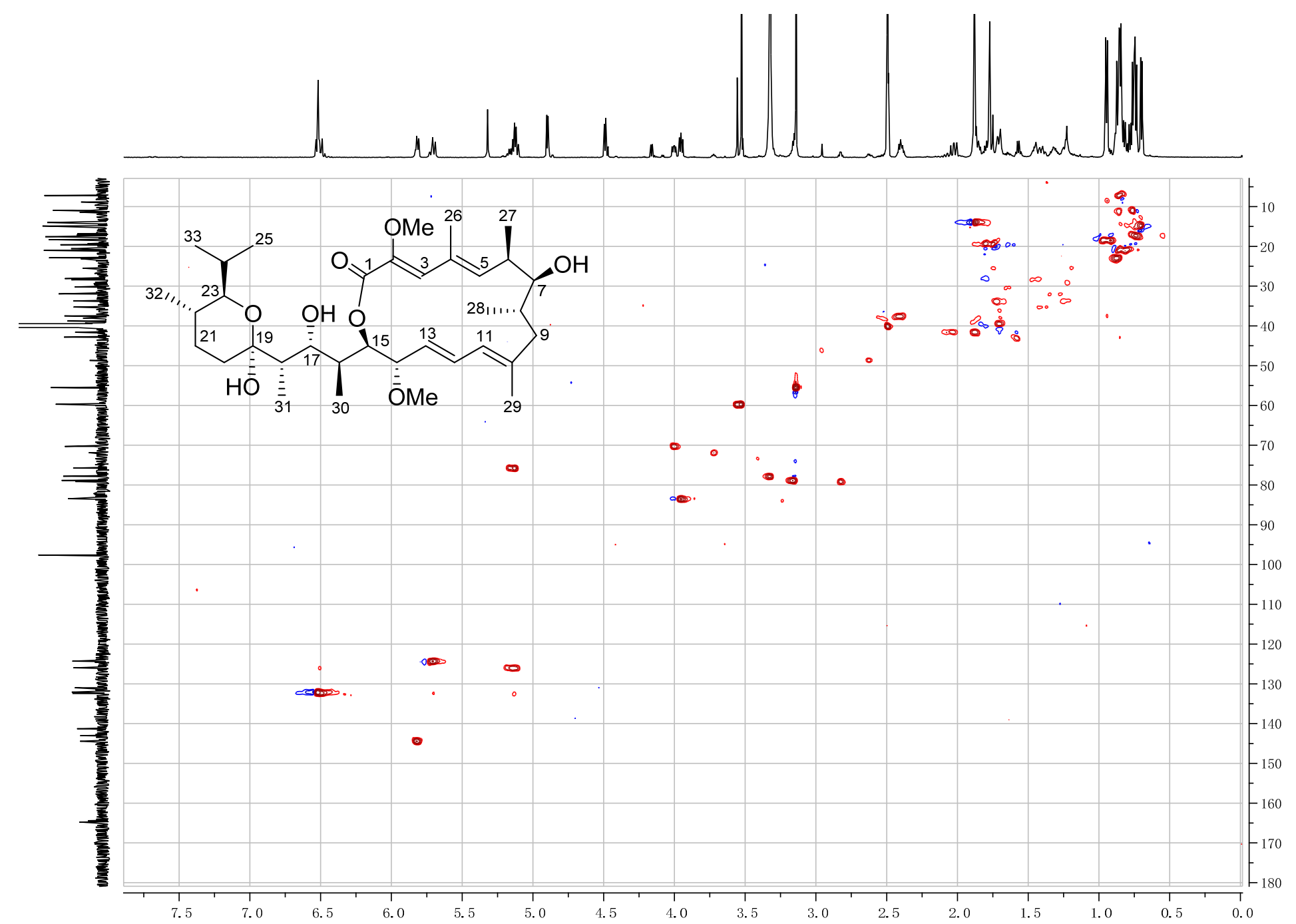

Figure S11. HSQC spectrum of the new compound 2 


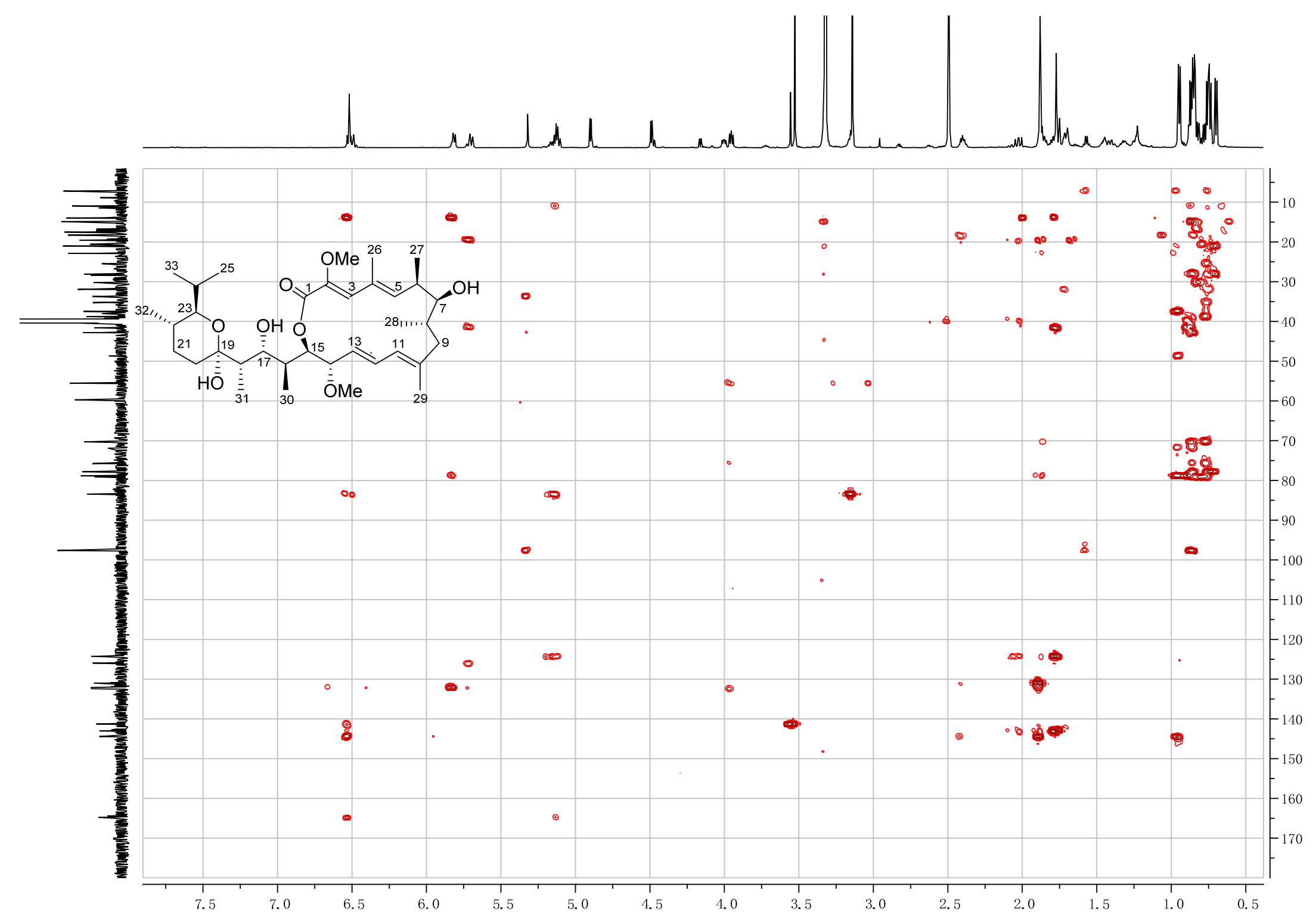

Figure S12. HMBC spectrum of the new compound 2 


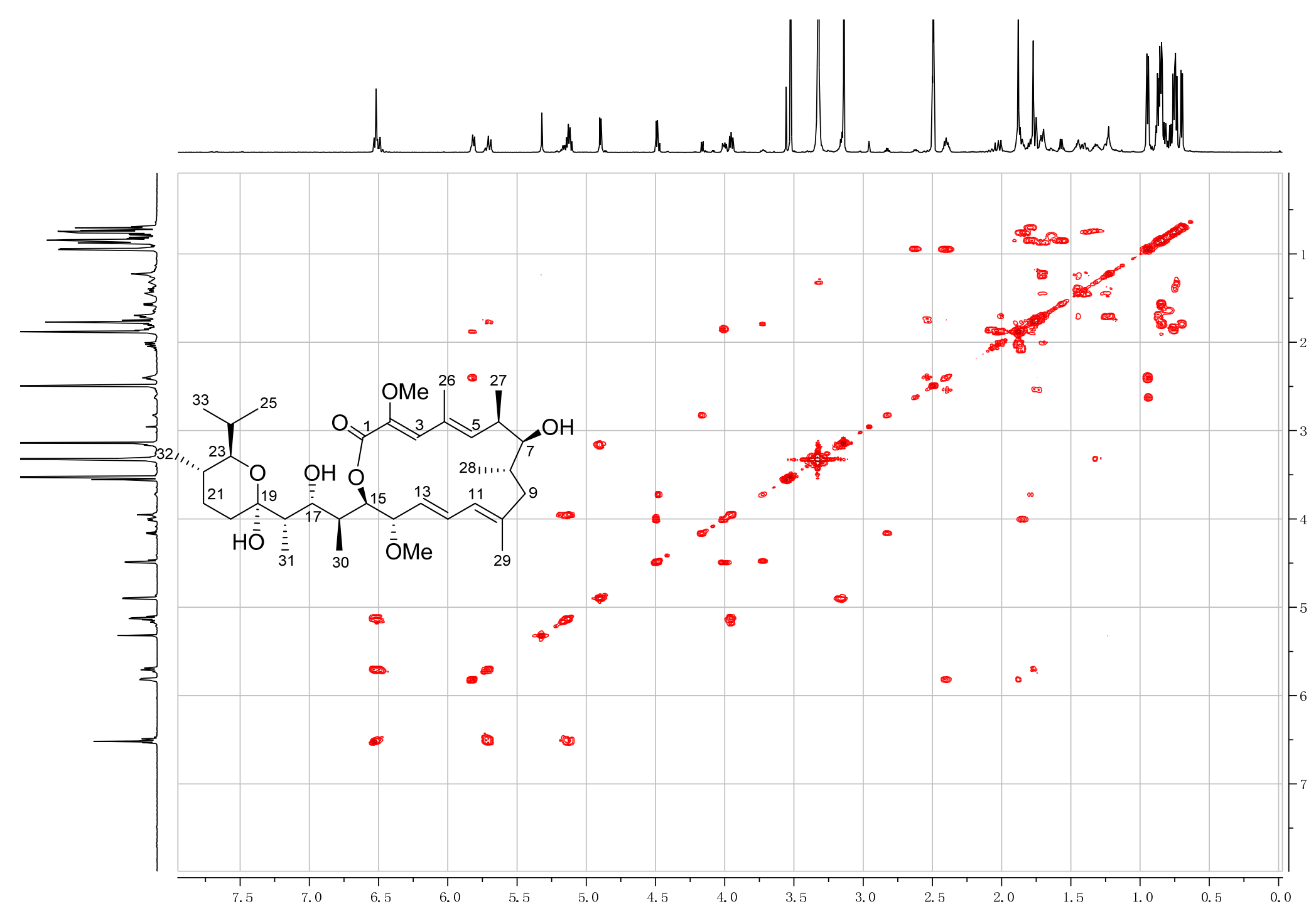

Figure S13. COSY spectrum of the new compound 2 


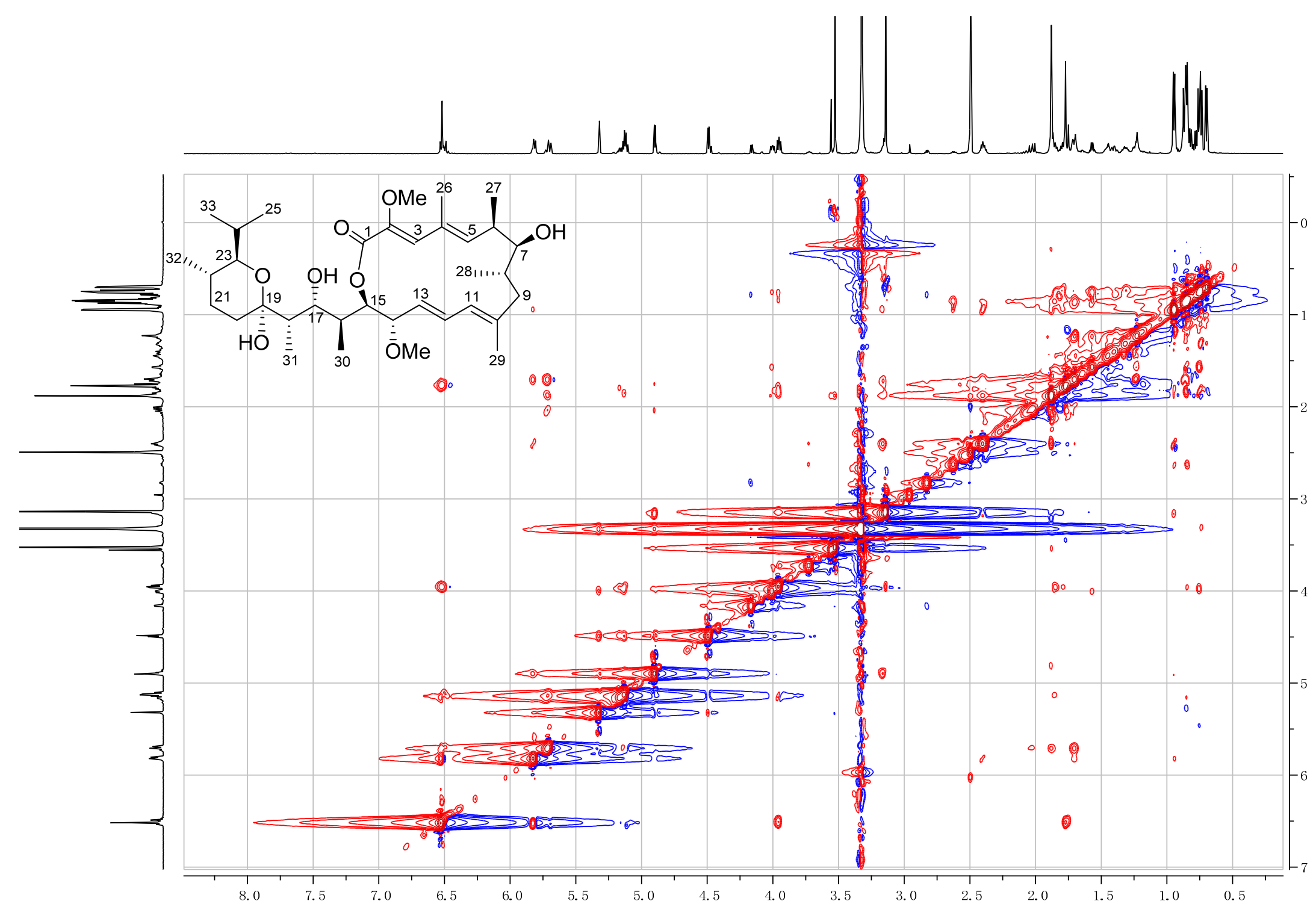

Figure S14. NOESY spectrum of the new compound 2 


\section{User Spectra}

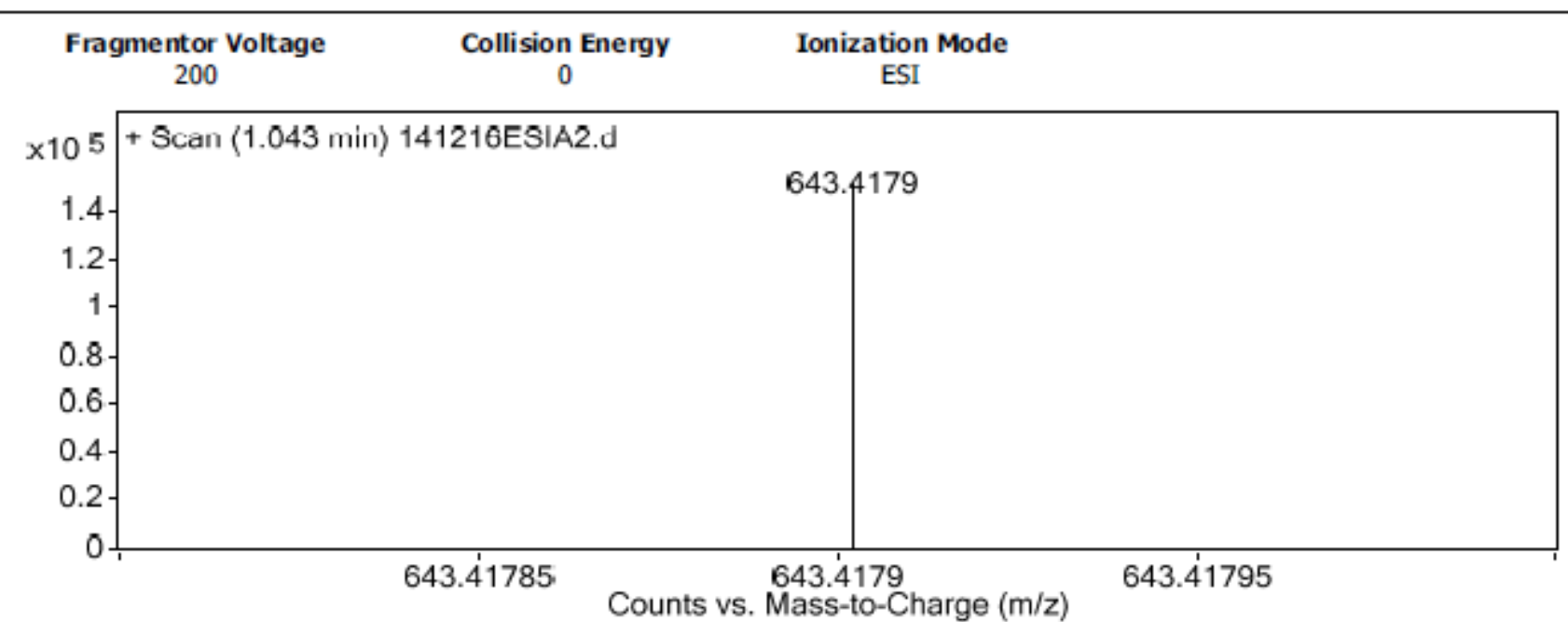

\begin{tabular}{|c|c|c|c|}
\hline \multicolumn{4}{|l|}{ Peak List } \\
\hline$m / z$ & $\mathbf{z}$ & \multicolumn{2}{|c|}{ Abund } \\
\hline 1263.8454 & 1 & \multicolumn{2}{|c|}{154996.63} \\
\hline \multicolumn{4}{|c|}{ Formula Calculator Element Li } \\
\hline Element & Min & & Max \\
\hline C & & 0 & 200 \\
\hline $\mathrm{H}$ & & 0 & 400 \\
\hline 0 & & 0 & 15 \\
\hline $\mathrm{Na}$ & & 1 & 1 \\
\hline
\end{tabular}

Formula Calculator Results

\begin{tabular}{|l|r|r|r|r|r|}
\hline Formula & CalculatedMass & Mz & Diff.(mDa) & Diff. (ppm) & DBE \\
\hline C36 H60 Na 08 & 643.4186 & 643.4179 & 0.7 & 1.1 & 6.5 \\
\hline
\end{tabular}

Figure S15. HRESI-MS spectrum of the new compound $\mathbf{3}$ 


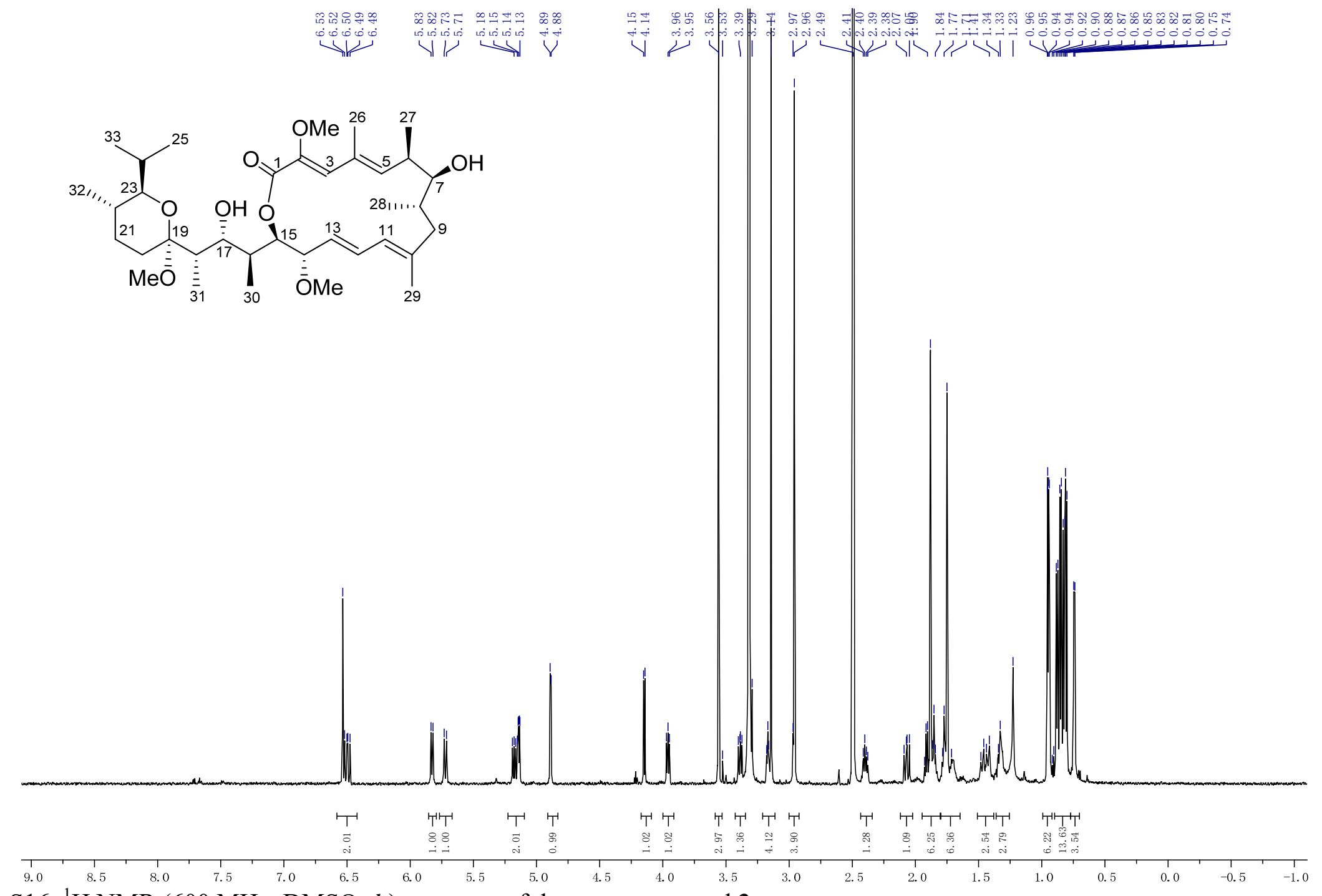

Figure S16. ${ }^{1} \mathrm{H}$ NMR $\left(600 \mathrm{MHz}, \mathrm{DMSO}-d_{6}\right)$ spectrum of the new compound 3 

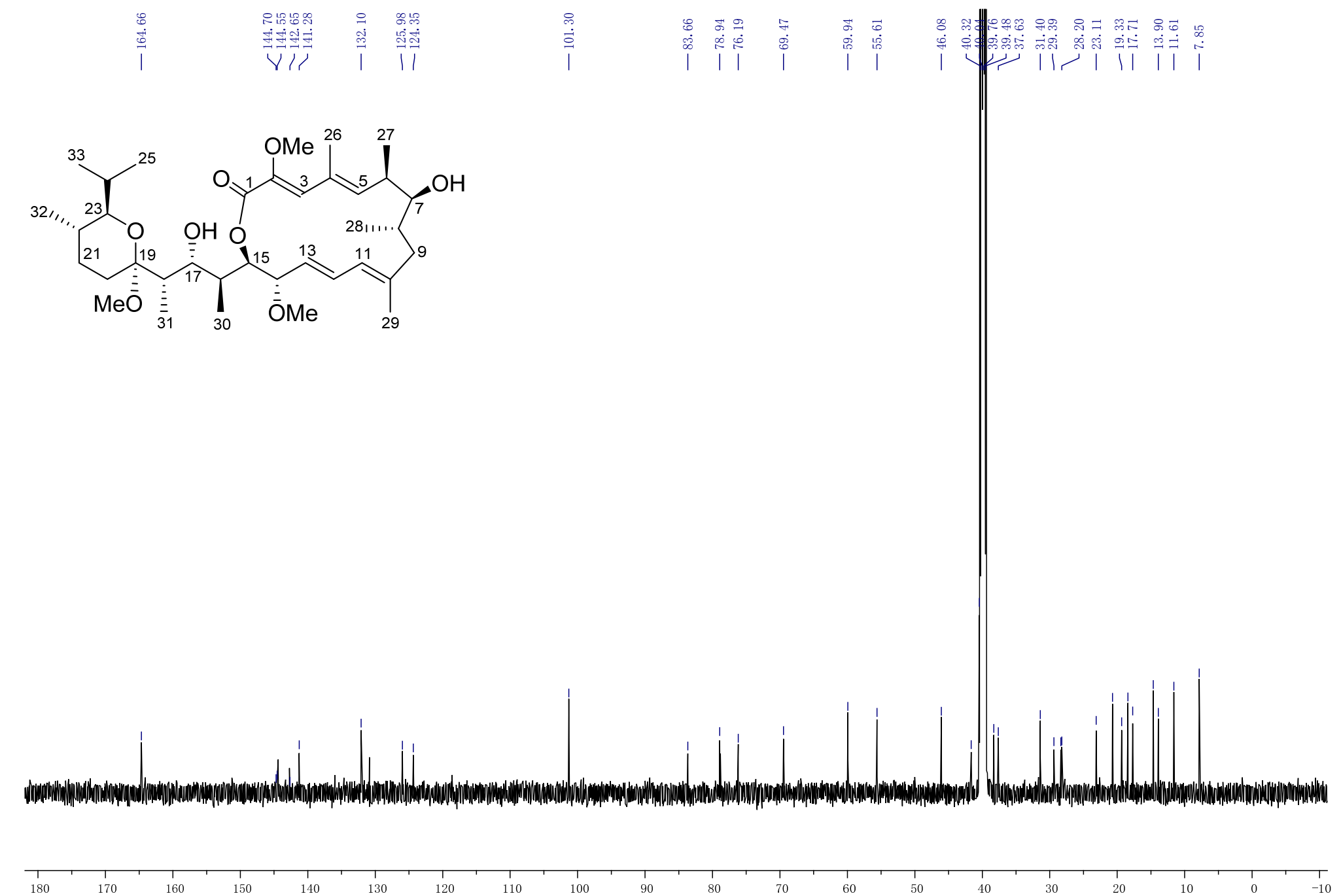

Figure S17. ${ }^{13} \mathrm{C}$ NMR $\left(150 \mathrm{MHz}\right.$, DMSO- $\left.d_{6}\right)$ spectrum of the new compound 3 


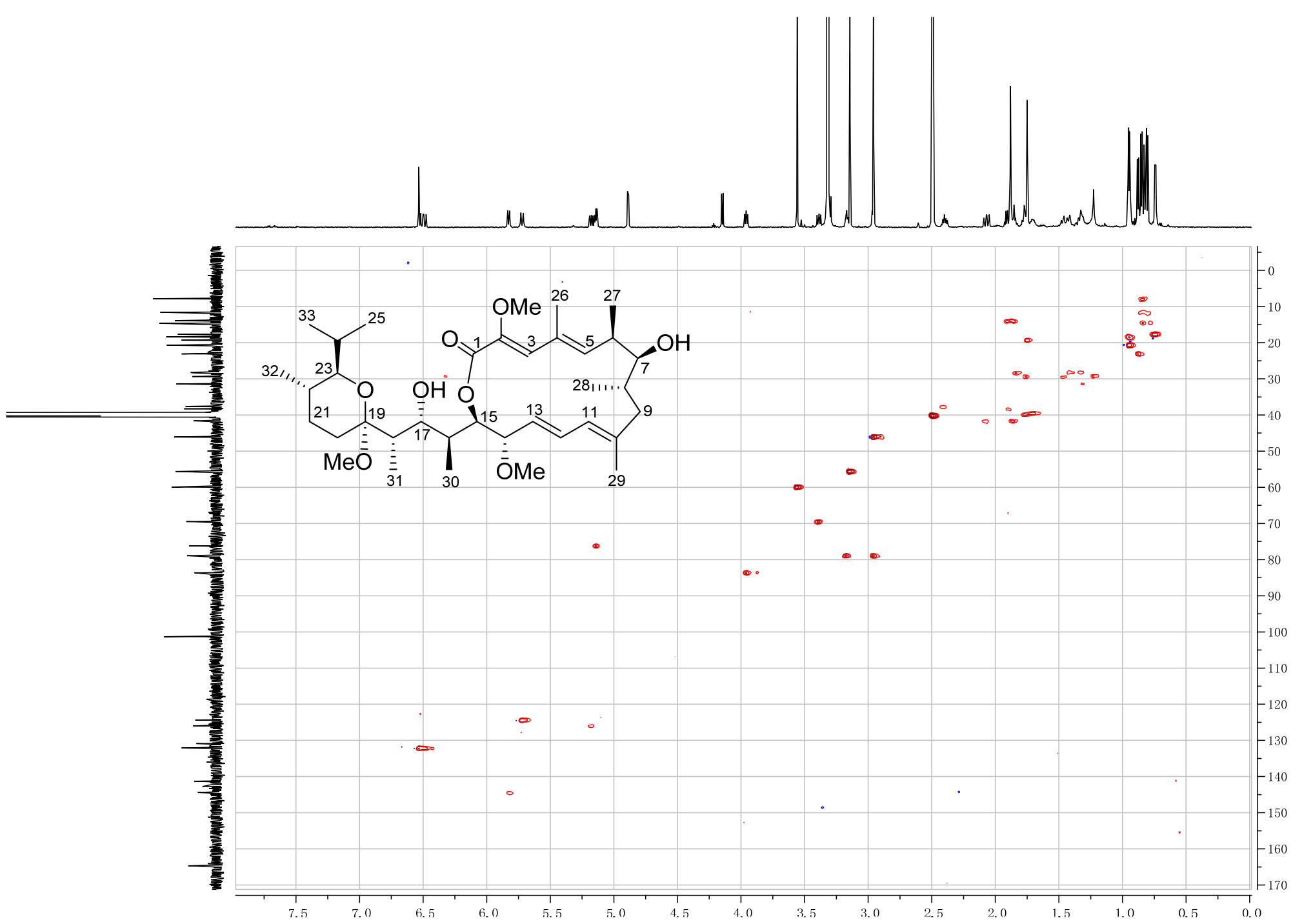

Figure S18. HSQC spectrum of the new compound $\mathbf{3}$ 


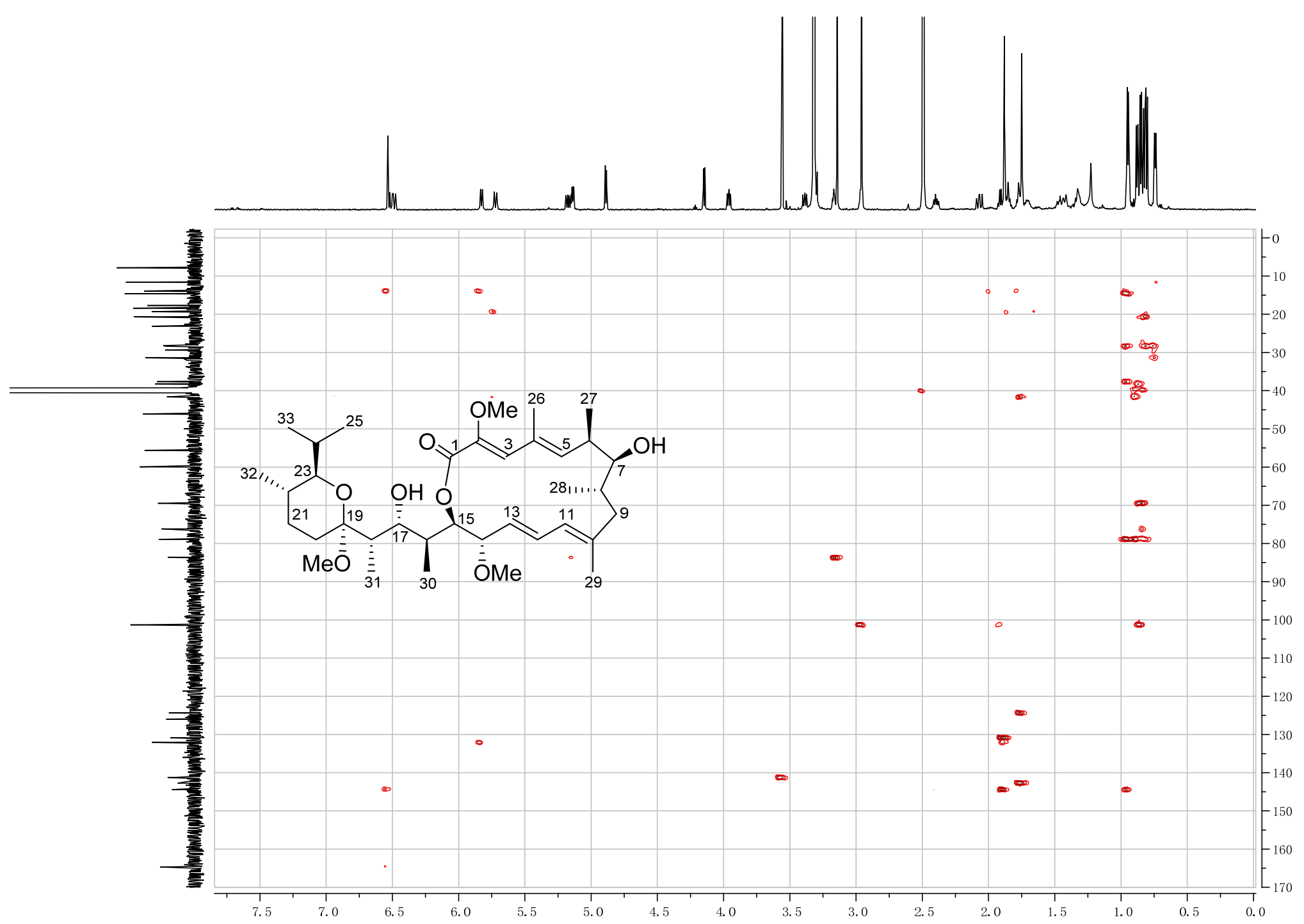

Figure S19. HMBC spectrum of the new compound $\mathbf{3}$ 


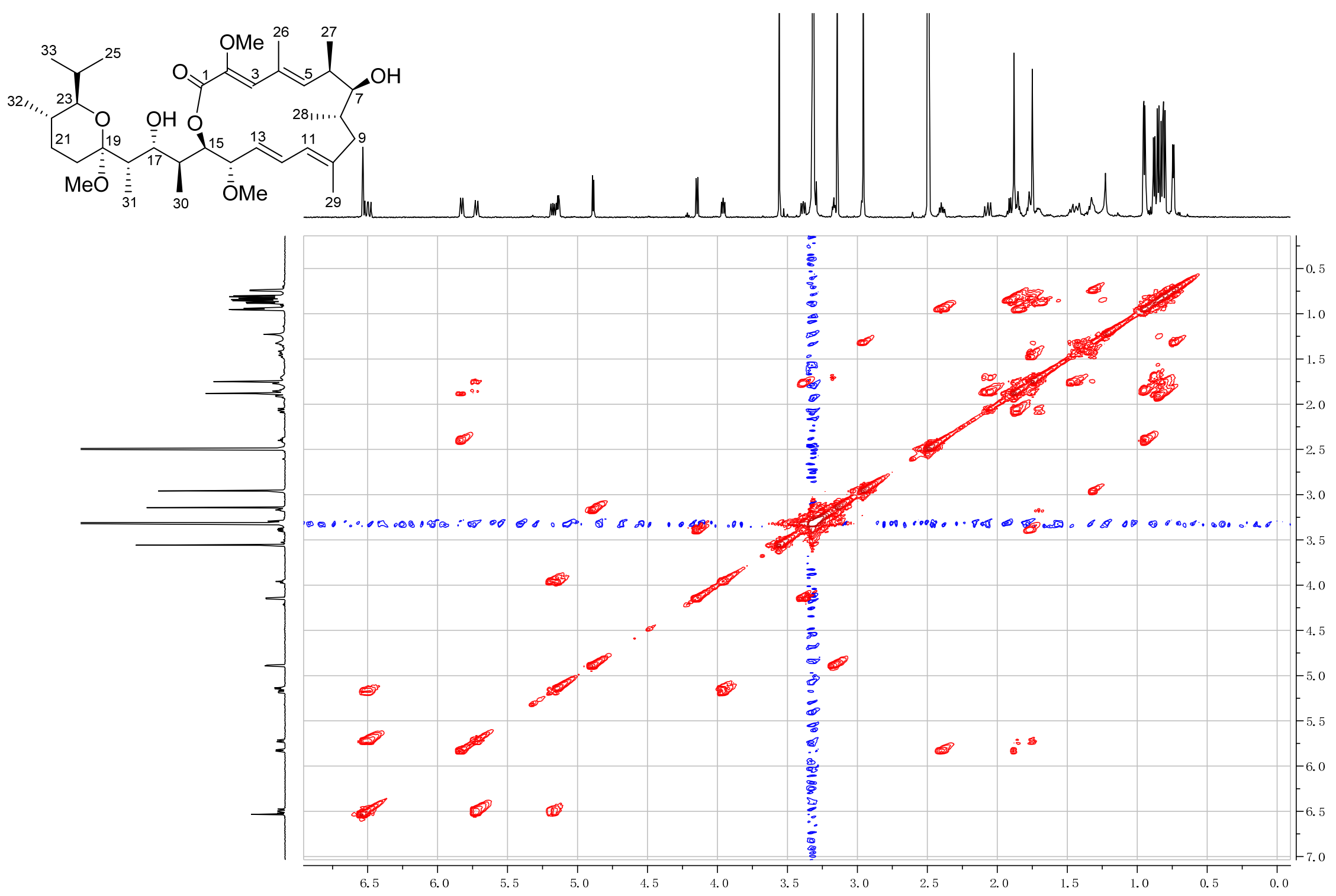

Figure S20. COSY spectrum of the new compound $\mathbf{3}$ 


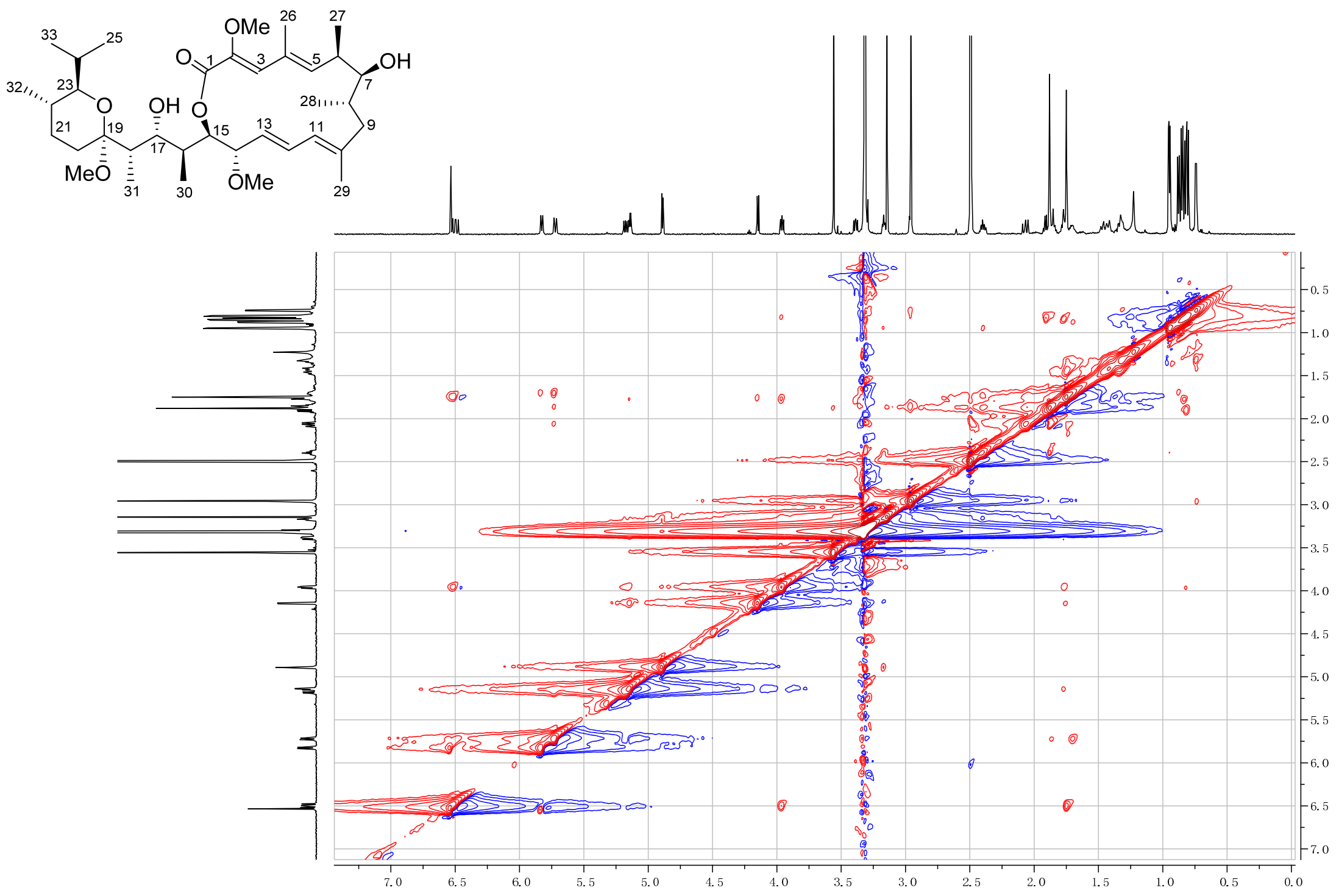

Figure S21. NOESY spectrum of the new compound $\mathbf{3}$ 


\section{User Spectra}

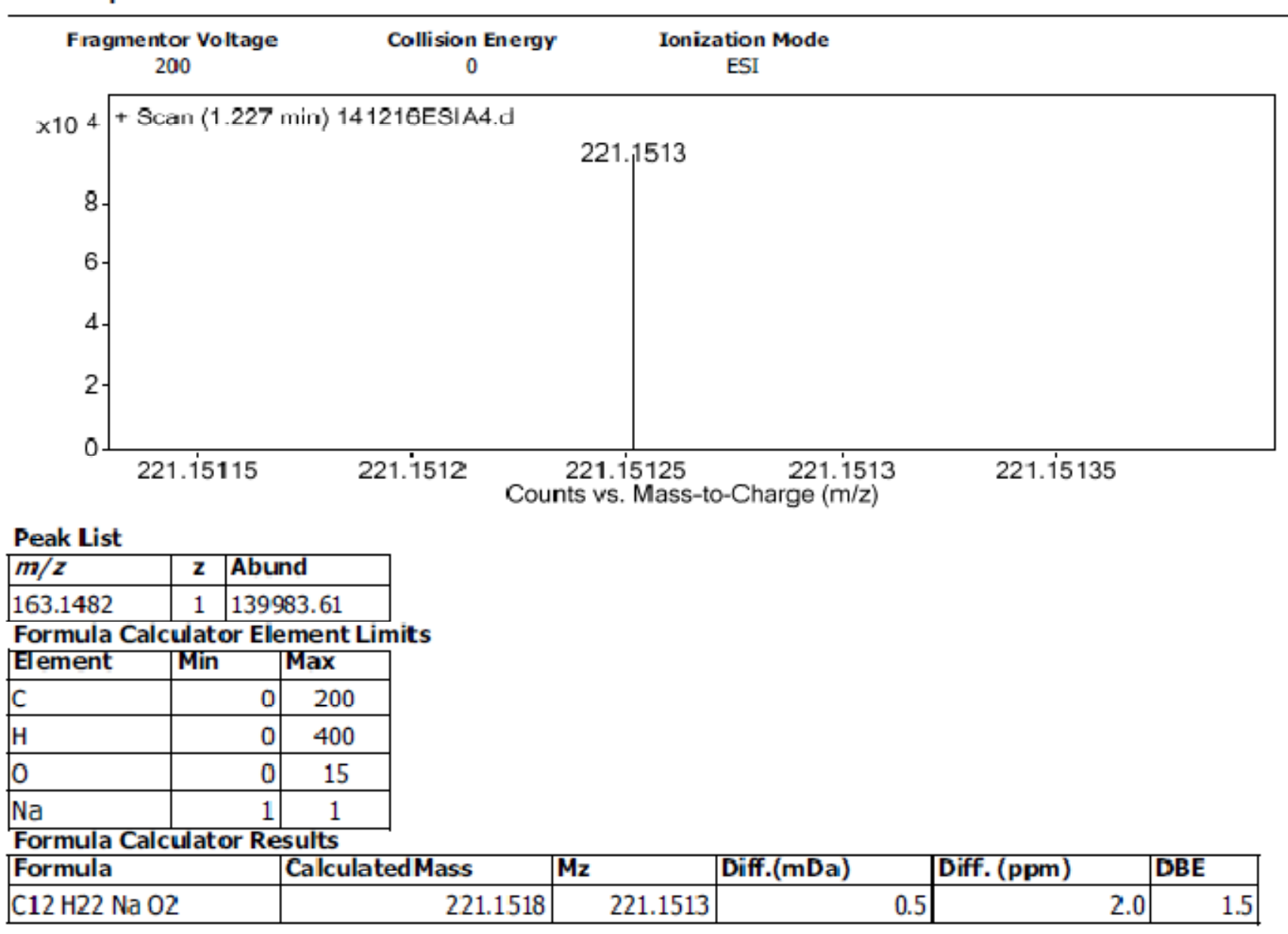

Figure S22. HRESI-MS spectrum of the new compound $\mathbf{1 0}$ 


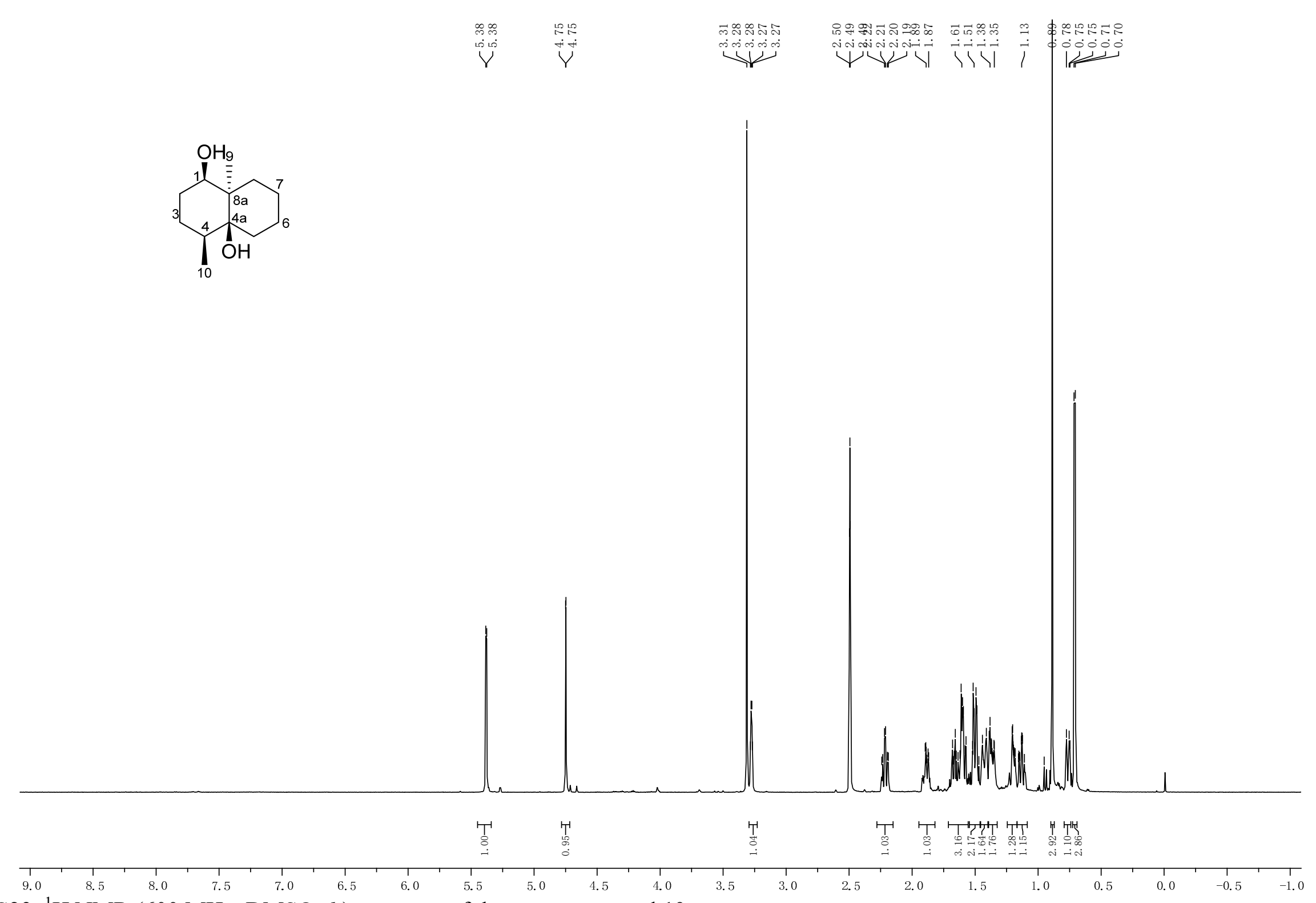

Figure S23. ${ }^{1} \mathrm{H}$ NMR $\left(600 \mathrm{MHz}, \mathrm{DMSO}-d_{6}\right)$ spectrum of the new compound 10 


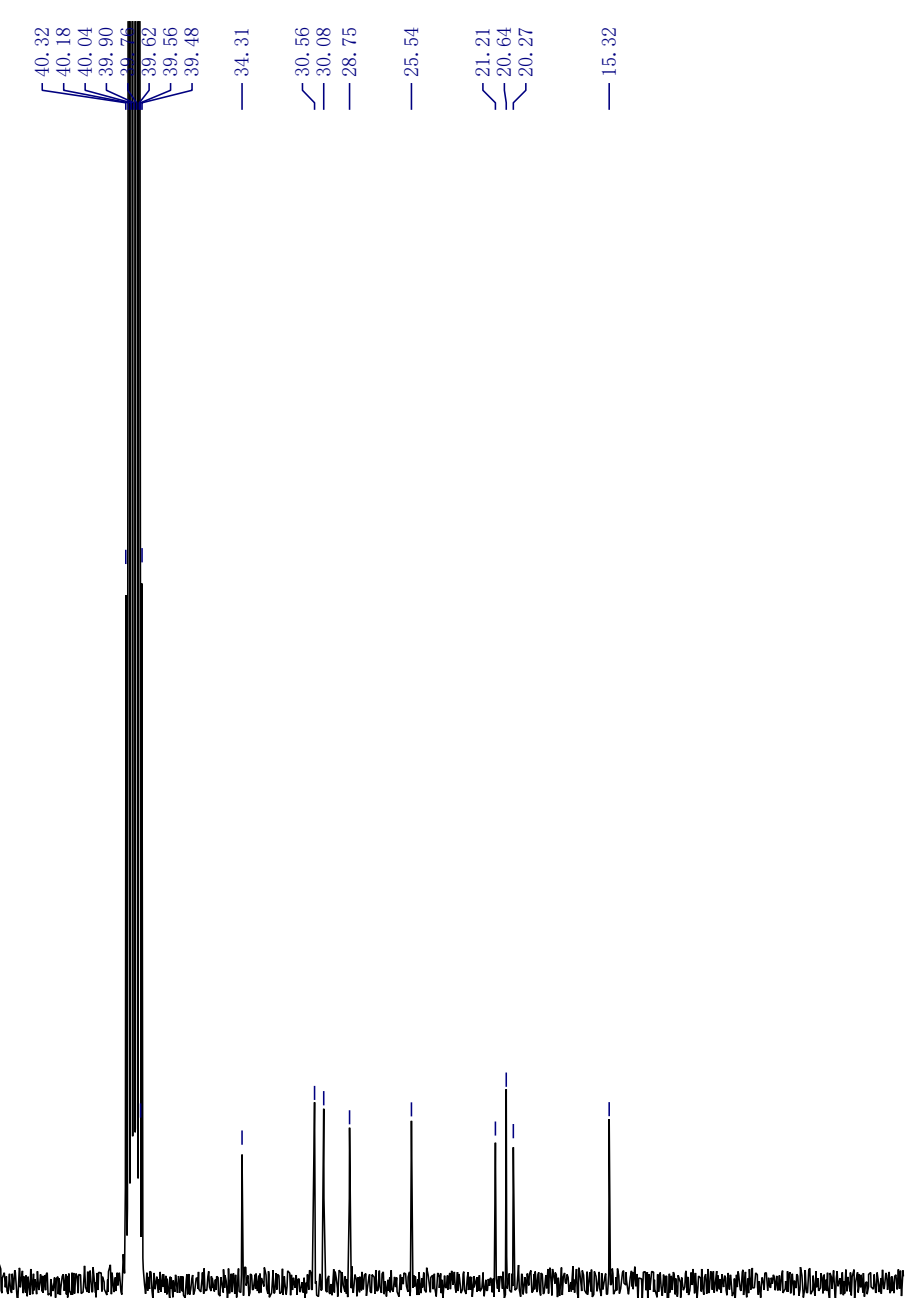

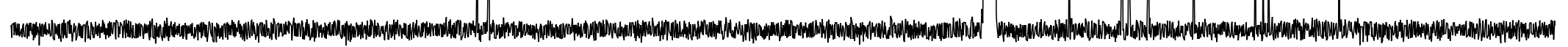
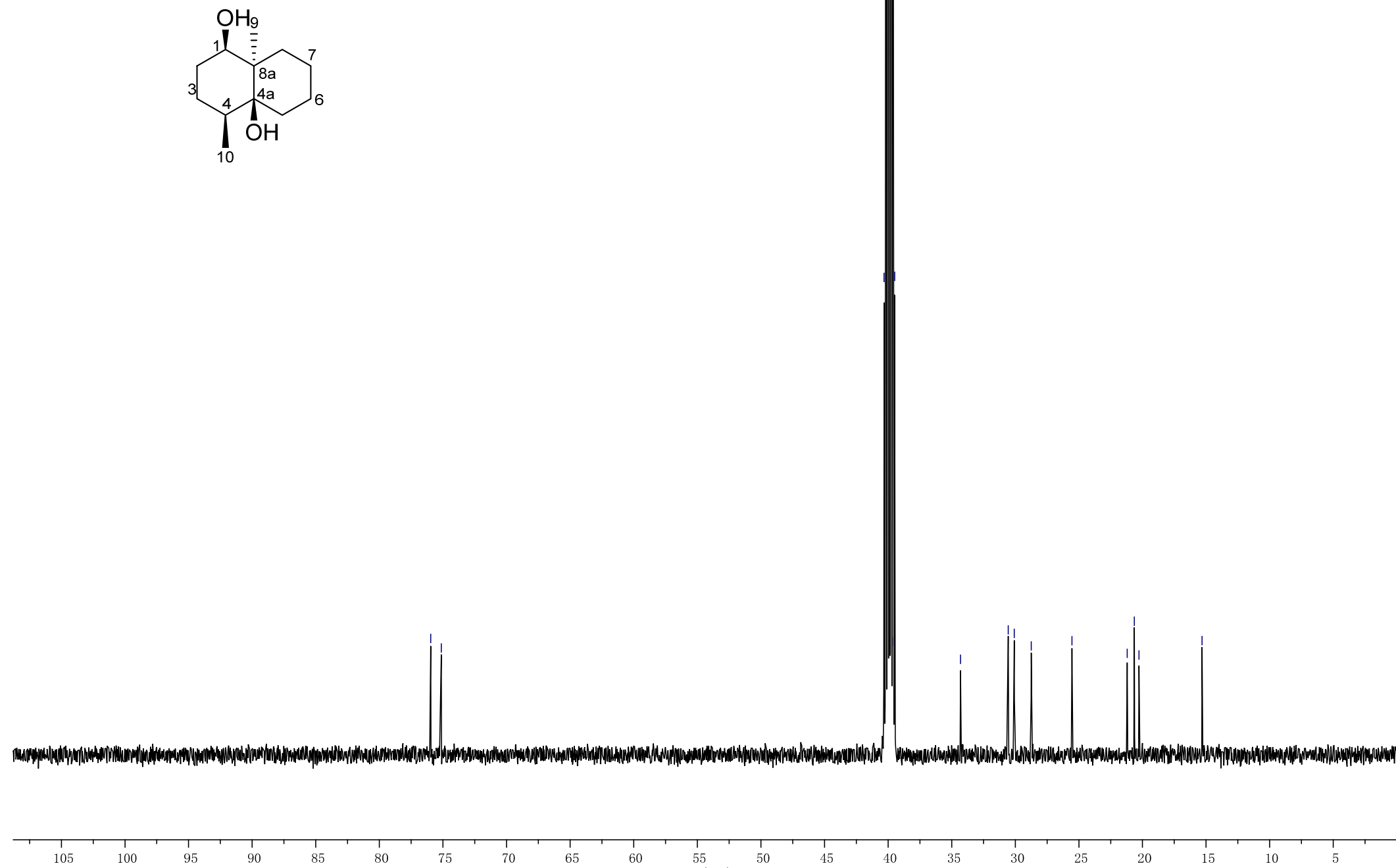

Figure S24. ${ }^{13} \mathrm{C}$ NMR $\left(150 \mathrm{MHz}, \mathrm{DMSO}-d_{6}\right)$ spectrum of the new compound $\mathbf{1 0}$ 


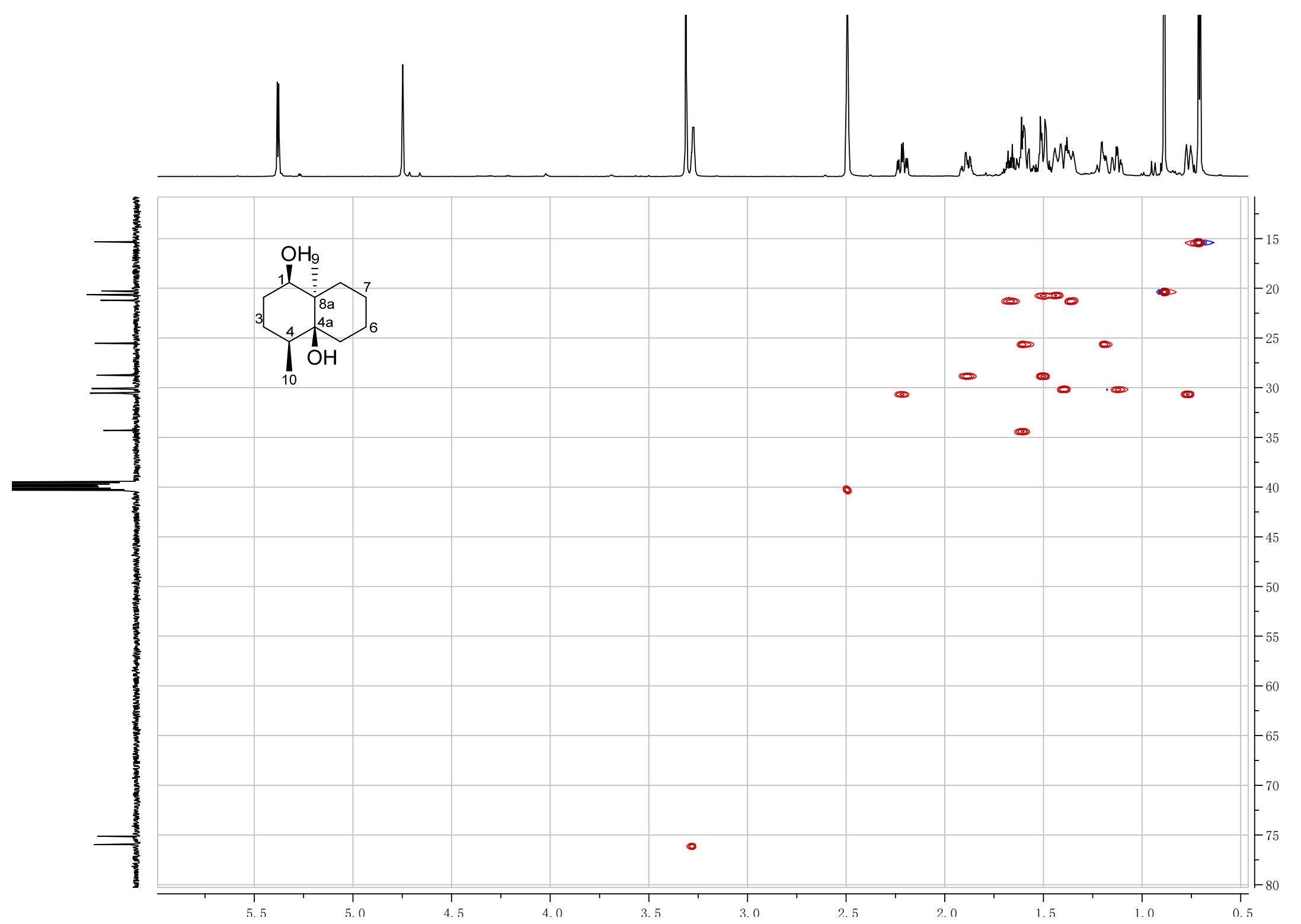

Figure S25. HSQC spectrum of the new compound $\mathbf{1 0}$

25 


$$
\text { 青然 }
$$




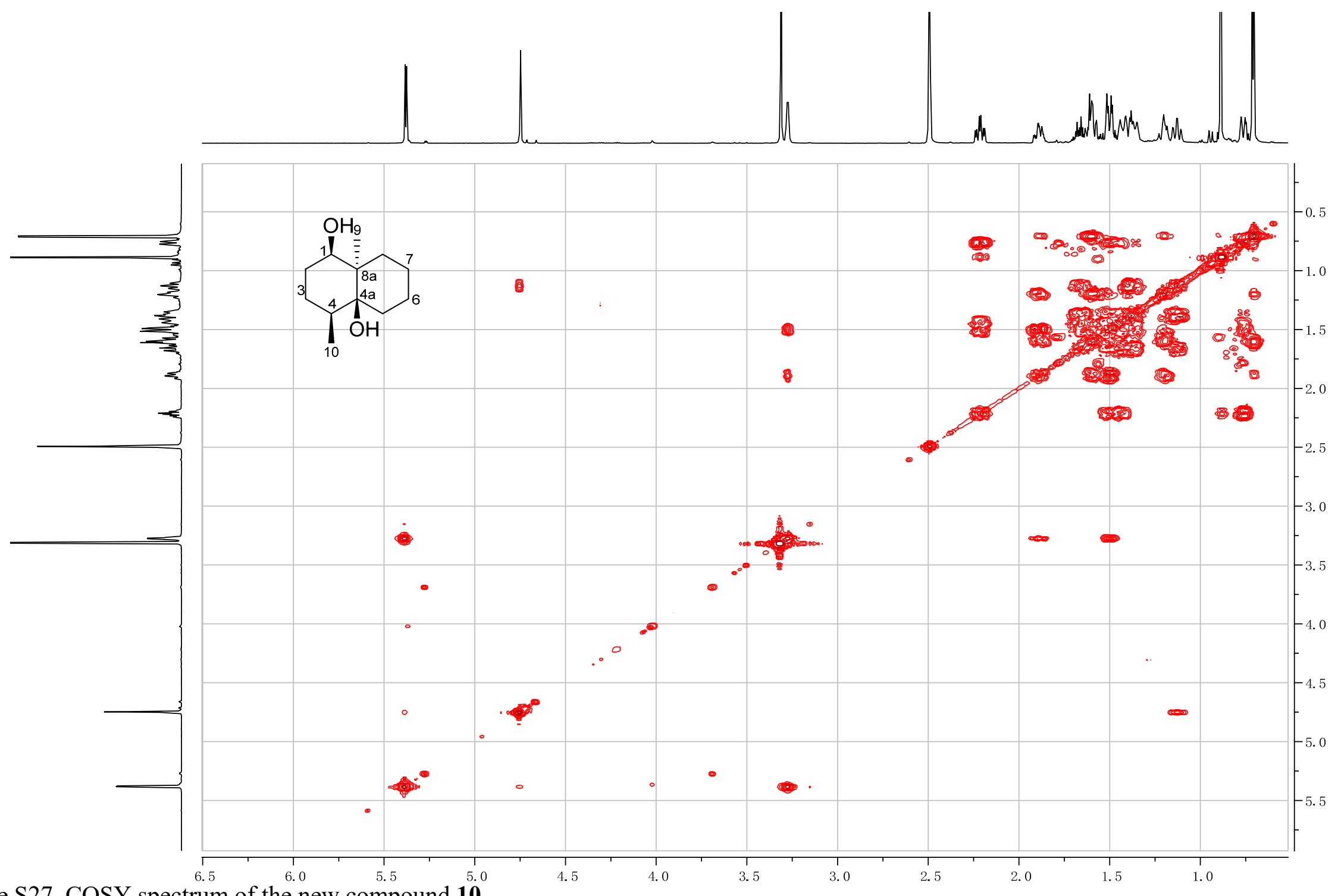

Figure S27. COSY spectrum of the new compound $\mathbf{1 0}$ 


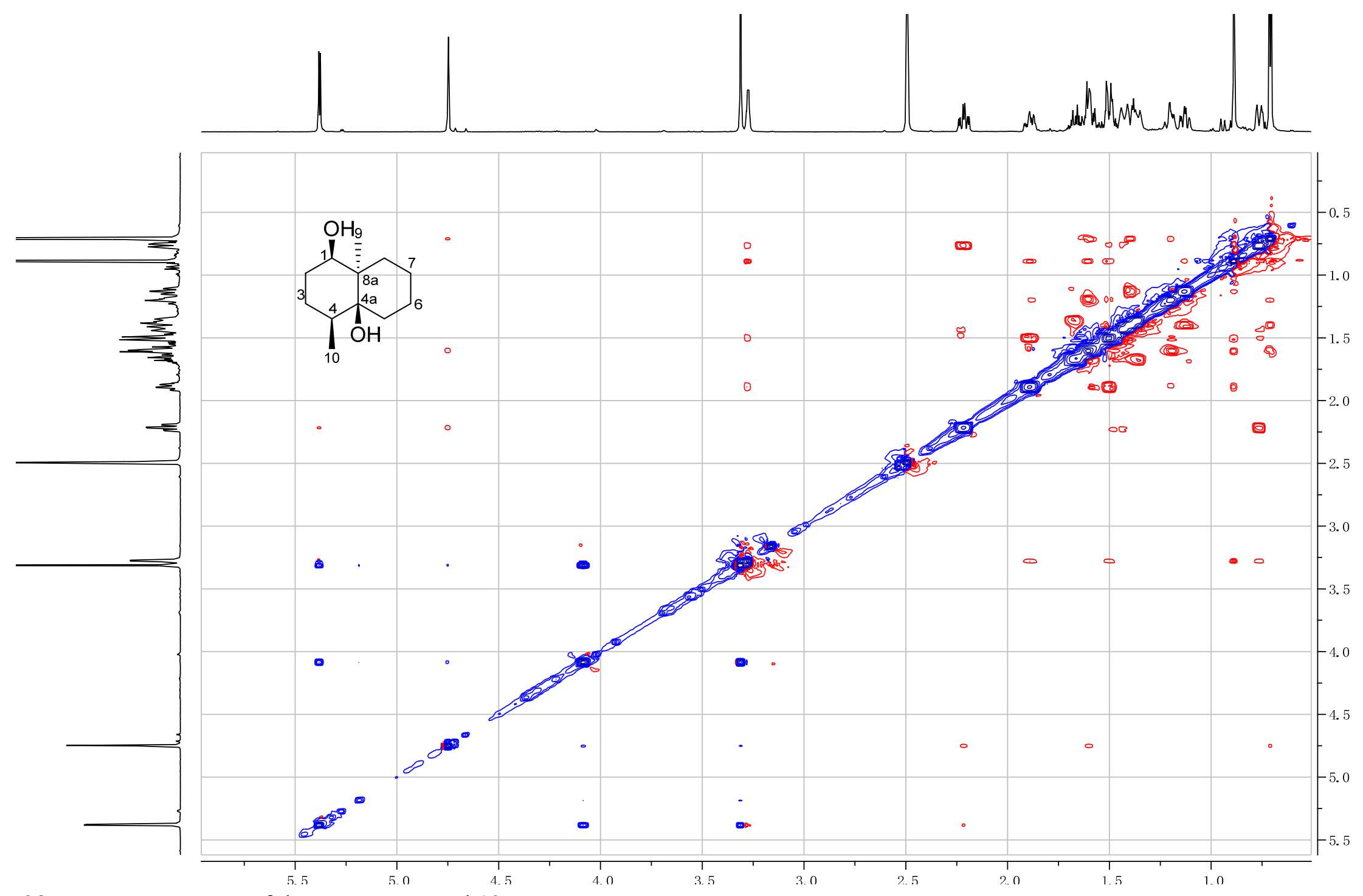

Figure S28. NOESY spectrum of the new compound $\mathbf{1 0}$ 


\section{User Spectra}

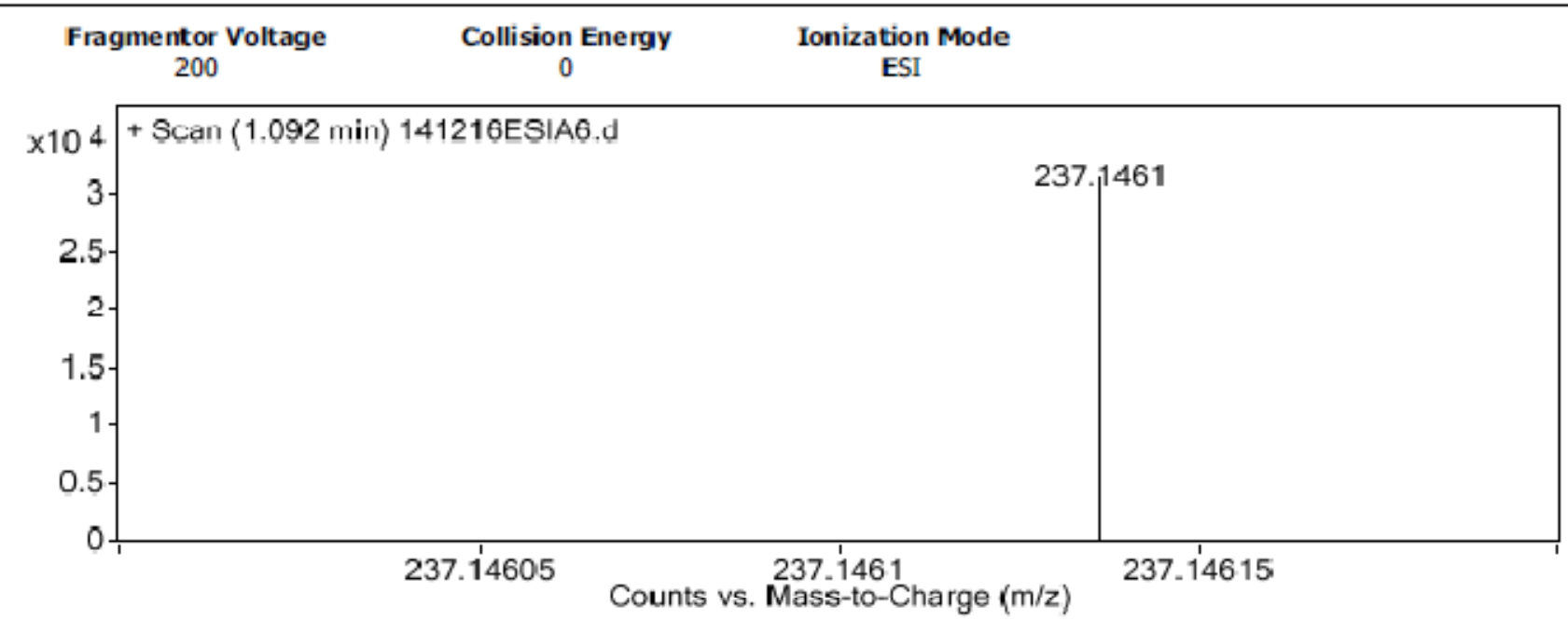

\begin{tabular}{|c|c|c|c|}
\hline$m / z$ & $z$ & Abul & \\
\hline 473.3451 & 1 & 9693 & 35.5 \\
\hline \multicolumn{4}{|c|}{ Formula Calculator Element Li } \\
\hline Element & Mir & & Max \\
\hline C & & 0 & 200 \\
\hline $\mathrm{H}$ & & 0 & 400 \\
\hline $\mathrm{O}$ & & 0 & 15 \\
\hline Na & & 1 & 1 \\
\hline
\end{tabular}

Formula Calculator Results

\begin{tabular}{|l|r|r|r|r|r|}
\hline Formula & CalculatedMass & Mz & Diff.(mDa) & Diff. (ppm) & DBE \\
\hline C12 H22 Na O3 & 237.1467 & 237.1461 & 0.6 & 2.4 & 1.5 \\
\hline
\end{tabular}

Figure S29. HRESI-MS spectrum of the new compound 11 


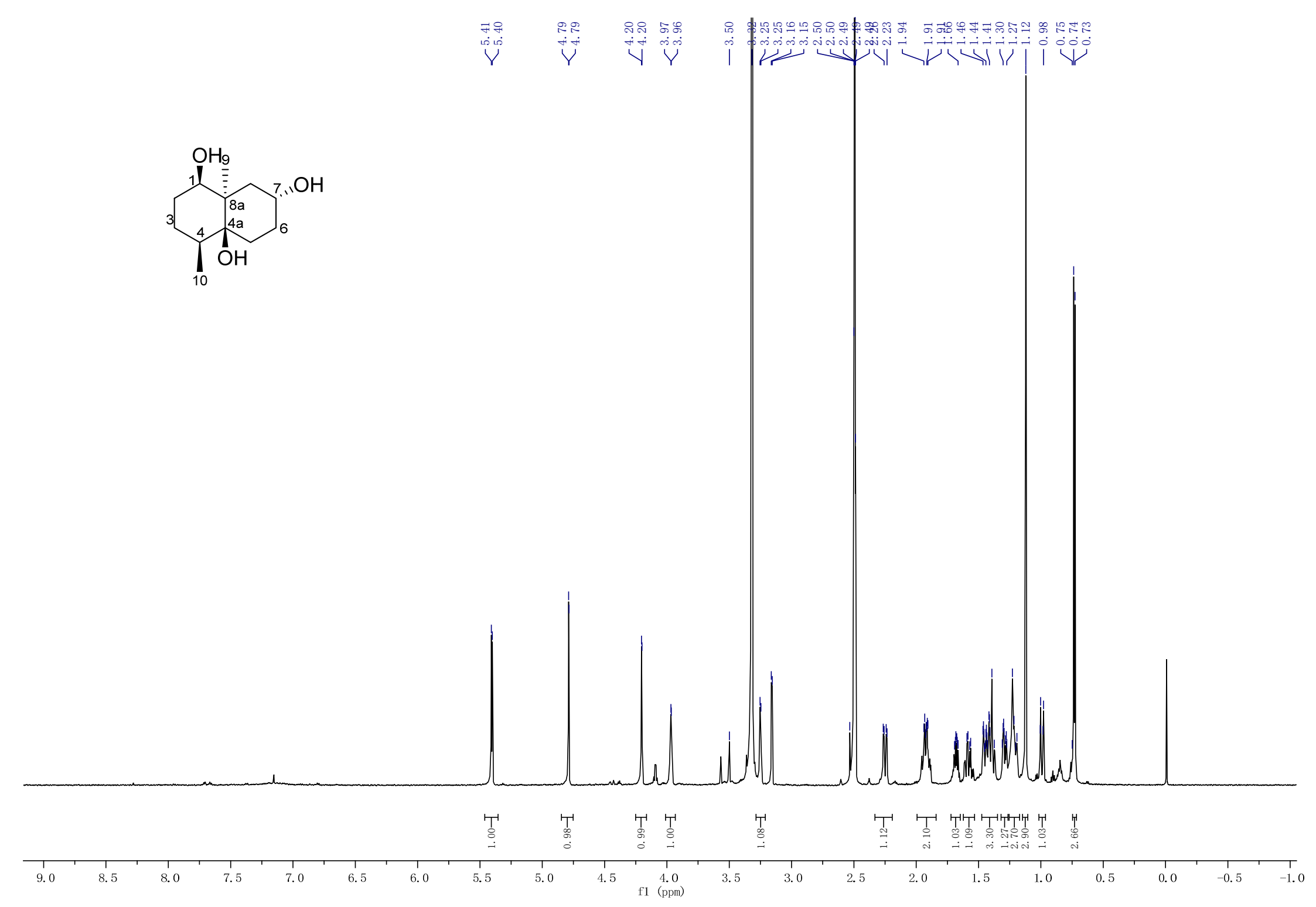

Figure S30. ${ }^{1} \mathrm{H}$ NMR (600 MHz, DMSO- $d_{6}$ ) spectrum of the new compound 11 


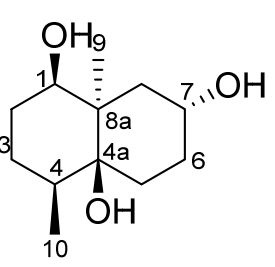
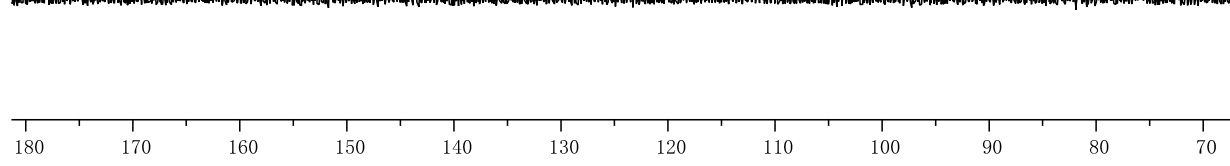

Figure S31. ${ }^{13} \mathrm{C}$ NMR $\left(150 \mathrm{MHz}, \mathrm{DMSO}-d_{6}\right)$ spectrum of the new compound 11 


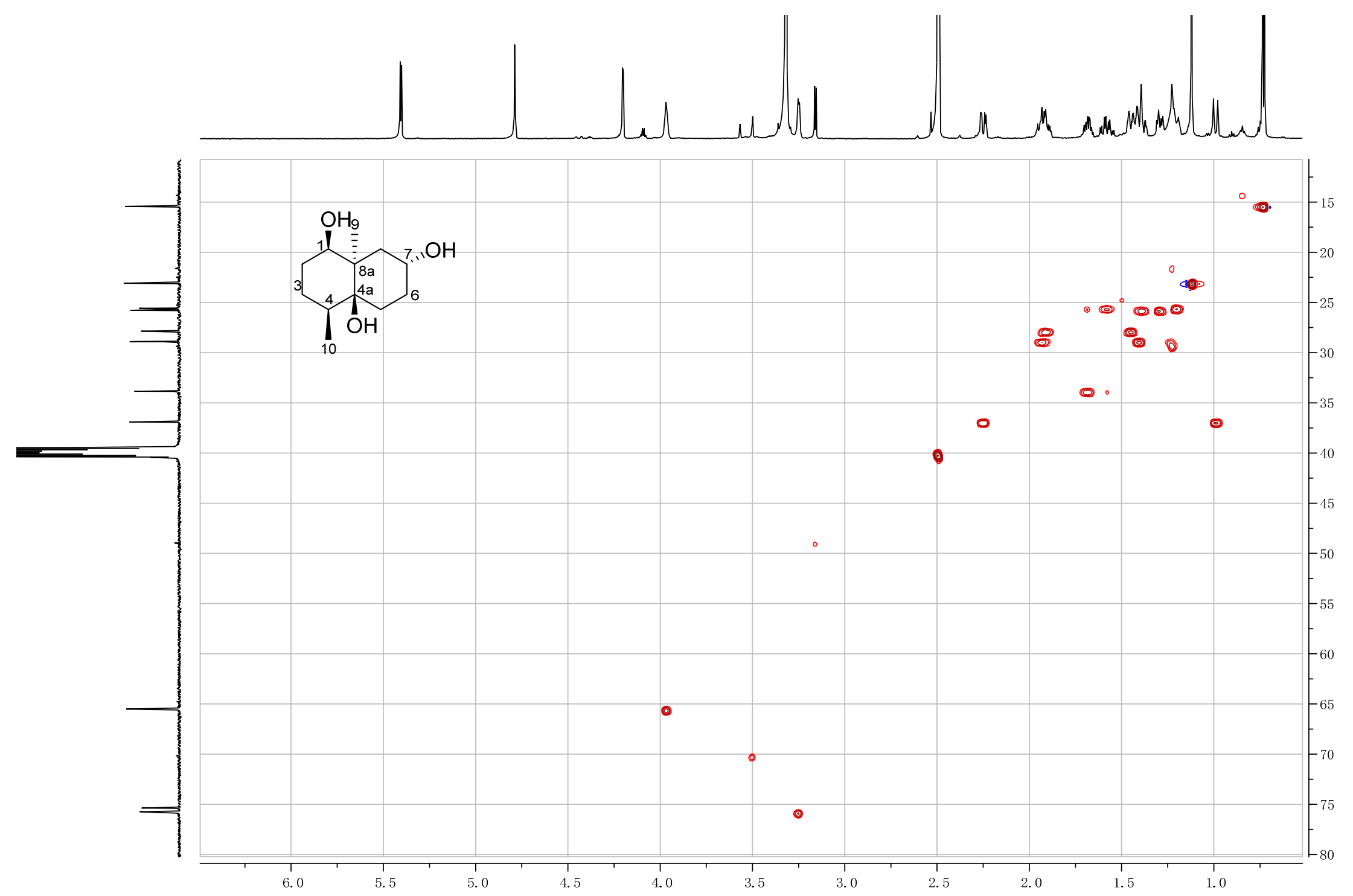

Figure S32. HSQC spectrum of the new compound 11 


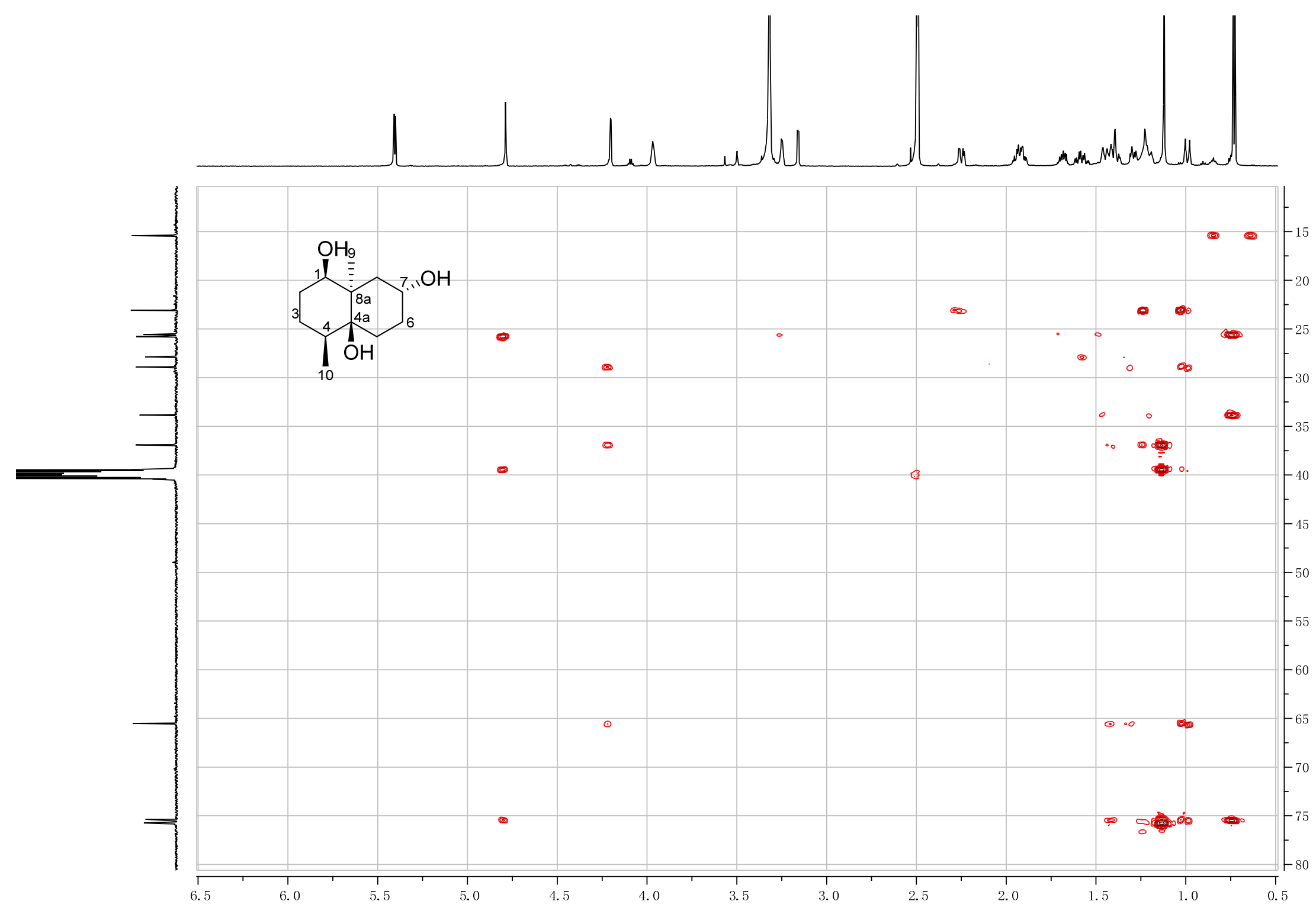

Figure S33. HMBC spectrum of the new compound 11 


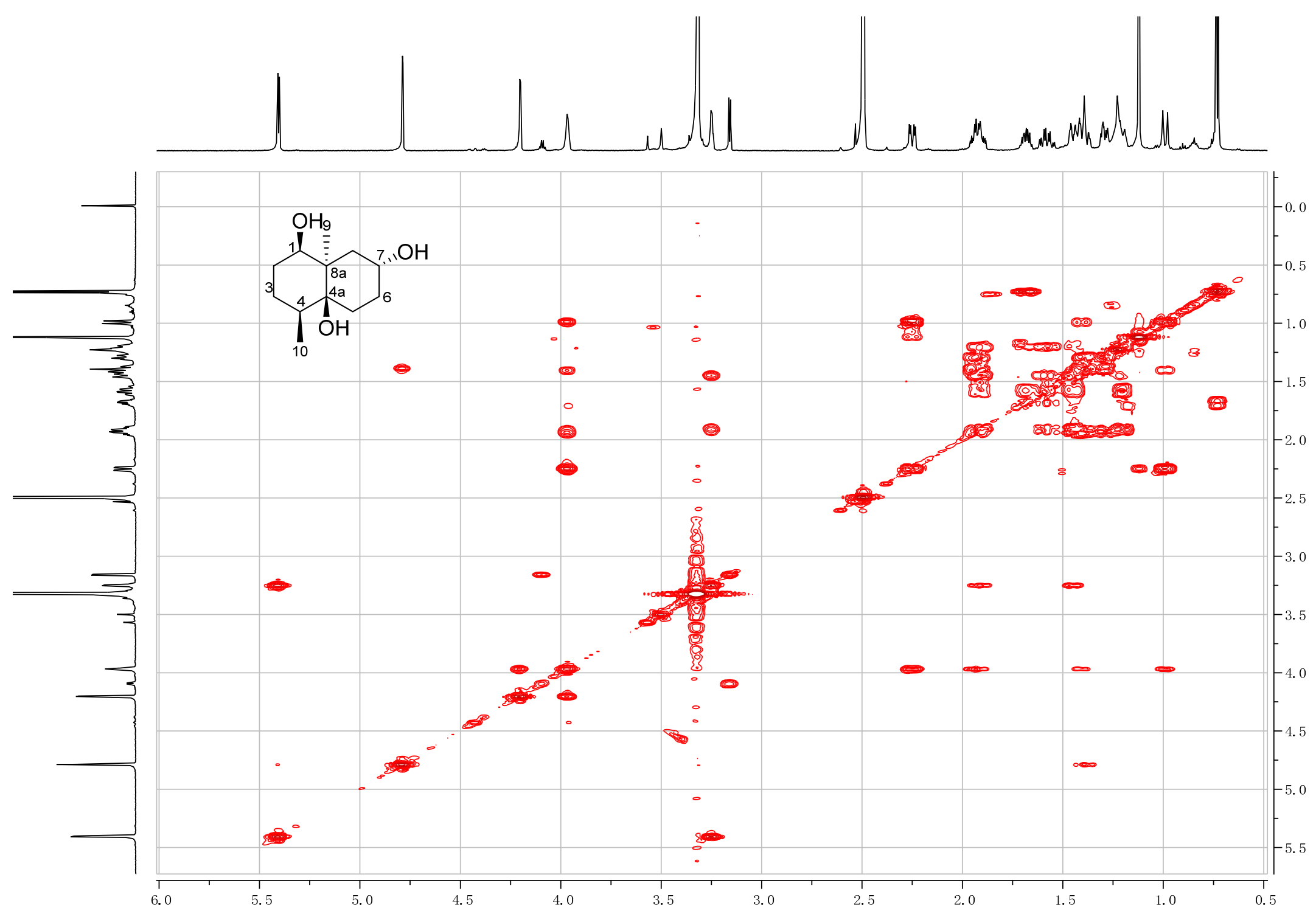

Figure S34. COSY spectrum of the new compound $\mathbf{1 1}$ 


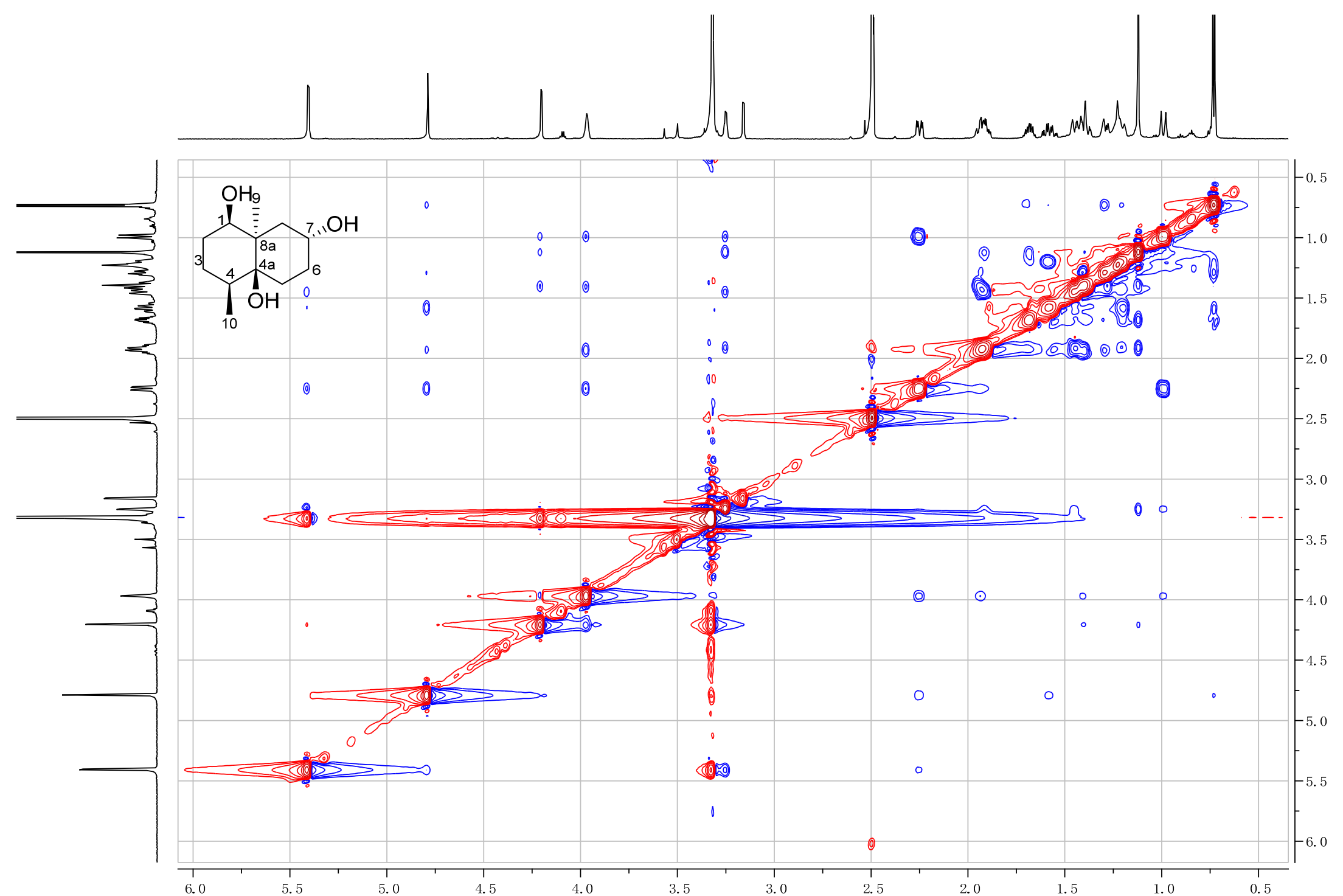

Figure S35. NOESY spectrum of the new compound 11 